\title{
Clean or dirty energy: evidence of corruption in the renewable energy sector
}

\author{
Caterina Gennaioli $^{1} \cdot$ Massimo $^{\text {Tavoni }}{ }^{2,3}$
}

Received: 3 September 2014/ Accepted: 24 February 2016/Published online: 16 March 2016

(C) The Author(s) 2016. This article is published with open access at Springerlink.com

\begin{abstract}
This paper studies the link between public policy and corruption for the case of wind energy. We show that publicly subsidized renewable energy can attract criminal appetites and favor the formation of criminal associations between entrepreneurs and politicians able to influence the licensing process. The insights of a simple model of political influence by interest groups are tested empirically using Italian data for the years 1990-2007. Using a difference in difference approach we quantify the impact of a Green Certificate policy aimed at supporting renewables, and find robust evidence that criminal association activity increased more in windy provinces after the introduction of the generous policy regime. The magnitude of the effect is large: the construction of an average wind park is associated with an increase in criminal activity of $6 \%$ in the treatment compared to the control group. Our findings show that in the presence of poor institutions, even well designed market-based policies can have an adverse impact. The analysis is relevant for countries that are generally characterized by heavy bureaucracies, weak institutions and by large renewable potential.
\end{abstract}

Keywords Corruption - Government subsidies · Natural resources · Renewable energy

JEL Classification $\mathrm{D} 73 \cdot \mathrm{O} 13 \cdot \mathrm{H} 23$

Caterina Gennaioli

c.gennaioli@lse.ac.uk

Massimo Tavoni

massimo.tavoni@feem.it

1 Centre for Climate Change Economics and Policy, and Grantham Research Institute on Climate Change and the Environment, London School of Economics and Political Science,

London WC2A $2 \mathrm{AE}, \mathrm{UK}$

2 Climate Change and Sustainable Development Programme, Fondazione Eni Enrico Mattei and Centro Euromediterraneo sui Cambiamenti Climatici, 20123 Milan, Italy

3 Department of Management and Economics, Politecnico di Milano, 20156 Milan, Italy 
In Italy, for example, power from wind farms is sold at a guaranteed rate of 180 Euros per kwh, the highest rate in the world. In a country where the Mafia has years of expertise at buying corrupt politicians and intimidating rivals, the result is perhaps inevitable, creating a new breed of entrepreneurs known as the lords of the wind. (The Telegraph 2010).

If you [an energy company] are interested in investing in Calabria, I can reassure you that it will be like a highway without toll gates. Wiretapping of an ongoing judicial inquiry about wind power (Corriere della Sera 2012).

\section{Introduction}

The aim of this paper is to study and quantify the effect of public policy on corruption. As an example of government intervention, we focus on the case of renewable energy. Renewable energy provides an interesting and policy relevant case for a variety of reasons. The energy sector is known to be both a target and a source of corruption, owing to the characteristics of the energy resources, the possibility of generating rents, and the key oversight role played by the government. For example, power generation and transmission as well as oil and gas are among the most bribery prone sectors, according to the Bribe Payers Index of Transparency International. ${ }^{1}$ International organizations such as the World Bank, which have been involved in the financing of energy infrastructure in the developing world, have recognized the need to reduce corruption, often by trying to strengthen governance. As Mauro (1998) suggests, the need for secrecy characterizing the corrupt deals implies that "it will be easier to collect substantial bribes on large infrastructure projects or highly sophisticated defense equipment than on textbooks or teachers' salaries". Complicated regulations and public spending are among the major factors that can promote corruption (Tanzi 1998) and both elements characterize renewable energy projects.

Renewable energy is also extremely policy relevant. Renewable sources such as wind and solar have been growing incredibly fast in recent years, especially in developed economies and largely spurred by public support schemes aimed at promoting low carbon energy alternatives. Moreover, policy instruments that promote market flexibility in the regulation of greenhouse gases have incentivized the trade of emission reduction credits between developed and developing countries (through the so-called Clean Development Mechanisms -CDM- of the Kyoto protocol). Renewable energy now represents the largest share of the CDM projects in the pipeline. Overall, renewable energy provides an important case for testing whether public incentives fuel rent-seeking and corruption in this sector.

Anecdotal evidence in Europe and elsewhere suggests the diffusion of corrupt practices related to public incentives for the renewable energy sector. Several official inquiries made by the Italian police have been made public, and have led to the arrest of managers and local politicians who allegedly used corrupt practices and bribes in order to obtain licenses to build wind farms. For example, according to an inquiry called "P3", the entrepreneur Flavio Carboni and a former politician Pasquale Lombardi set up a criminal association able to collect private funds from other entrepreneurs to pay bribes in exchange for wind farm permits in the region of Sardinia. ${ }^{2}$ Similar scandals have occurred in Spain, where 19

\footnotetext{
${ }^{1}$ http://bpi.transparency.org/bpi2011/.

${ }^{2}$ http://www.repubblica.it/cronaca/2010/07/08/news/arrestato_flavio_carboni-5471098/.
} 
persons were arrested in 2009 on charges of corruption in the wind sector. In the United States, the bankruptcy of the solar power manufacturing firm Solyndra has led to a controversy over the potential influence of the Department of Energy on the loan guarantee the firm was granted. Many countries are now evaluating public subsidies implemented over the past several years with the aim of promoting renewables. In most cases, ex post policy assessment has focused on issues of efficiency and effectiveness, but has essentially disregarded the role of the main political economy factors at play. To our knowledge, this is the first attempt to study whether public incentives for renewable energy resources can lead to an increase in illegal activities.

The main contribution of the paper is to understand whether the presence of a renewable natural resource, such as wind energy, creates scope for rent seeking practices and corruption when public incentives make it profitable to harvest the renewable potential. We do so by first sketching a simple theory of political influence by interest groups, which yields predictions on the relation between corruption, renewable resources and public subsidies. These insights are tested on a panel dataset of Italian provinces for the 1990-2007 period. In the analysis we can exploit the presence of the renewable energy resource (e.g., wind potential) as inducing an exogenous variation in the expected rent opportunities which allows us to identify a treatment and a control group of provinces. Using a difference in difference approach we provide strong evidence that supports our model, establishing that the expectations of high public incentives in the wind energy sector have fueled corruption as measured by the level of criminal association activity. Our main finding is that criminal association activity increased more in the high-wind provinces of the treatment group after the introduction of the generous public policy regime. The magnitude of the effect is significant: for an average wind park (of $10 \mathrm{MW}$ ) installed after 1999, and which receives about 1.5 Million euro per year in public support, the number of criminal association offenses has increased by $6 \%$ in the windy provinces compared to the less windy ones.

Overall, the paper points out that even well designed market-based policies can have an adverse impact where institutions are poorly functioning. This effect would be greater in places with high resource potential. This has important normative implications, especially for countries which are characterized by abundant renewable resources and weak institutions, and thus are more susceptible to the private exploitation of public incentives.

Related literature The paper is mainly related to the literature on corruption, which has shown how highly regulated environments that render bureaucrats more powerful favor the spread of corruption practices (Murphy et al. 1993; Tanzi 1998). ${ }^{3}$ Several studies have found that corruption is more detrimental to economic growth than taxation (Shleifer and Vishny 1993; Fisman and Svensson 2006), due to the uncertainty and secrecy required by the bribing process and the fact that corrupt deals cannot be enforced in courts. Moreover, corrupt officials might slow down the administrative process in order to collect more bribes (Myrdal 1968; Kaufmann and Wei 1998). Although we cannot analyze the effect of corruption on the economic efficiency of renewable energy projects, we contribute to this literature by finding evidence of corruption in a heavily regulated sector. To our knowledge, our paper is the first which is able to quantify the impact of renewable energy subsidies on corruption. We also present suggestive evidence that more corrupt provinces have actually attracted a higher number of wind energy projects, eventually accelerating the development of the wind sector. This is in line with Dreher and Gassebner (2013) who

\footnotetext{
3 Olken and Pande (2012), Sequeira (2012) and Svensson (2005) provide a comprehensive review of the literature on corruption.
} 
provide evidence supporting the "grease the wheels" hypothesis and find that in highly regulated environments, corruption eases firm entry.

Focusing on the effect of a raise in the expected rents from wind energy due to a government intervention, our study is also related to a number of papers that have analyzed the impact of natural resource rents on corruption, political institutions and state stability (Bhattacharyya and Hodler 2010; Arezki and Bruckner 2011; Vincente 2010). Vincente (2010) for example, analyzes the effects of an oil discovery announcement in the Island of Sao Tome and Principe. The author finds that the announcement increased the value of being in power for politicians and this in turn created scope for resource mis-allocation, such as vote-buying. Compared to Vincente, we are interested in the effects of a government intervention supporting renewables on the behavior of economic and political agents, namely the entrepreneurs operating in the wind energy sector and the local bureaucrats who grant authorization permits. In this sense our paper is somewhat related to the literature on the effect of political connections (Fisman 2001), which studies how firms take advantage of being connected to a politician by circumventing regulation and securing permits.

The paper also speaks to the literature which studies the effect of public spending on economic and political outcomes. According to this literature higher levels of public spending can be associated to worse outcomes. In particular, Tanzi and Davoodi (1997) present cross country evidence showing a positive correlation between public investment and corruption. Hessami (2010) detects a positive relationship between the perceived level of corruption and the share of spending on health and environmental protection. We take a micro-level perspective and highlight that the presence of the natural resource, when supported by public policy, can attract criminal appetites and favor the formation of criminal associations. In this context, the actual investments in the sector are not exogenous but driven by the presence of a well established criminal association between entrepreneurs and politicians able to influence the authorization process and thereby receive significant public funds.

The paper proceeds as follows: In the next section we discuss a framework which generates testable implications on the relationship between level of wind, corruption and the development of the wind sector, Section 3 describes the data and the institutional background, in Sect. 4 we outline the empirical strategy and present the empirical results from testing the model, while the final section concludes.

\section{A simple theory of corruption in the renewable energy sector}

In this framework entrepreneurs can influence bureaucrats or local politicians through bribes. ${ }^{4}$ Each province is populated by a politician and a number of entrepreneurs who decide either to invest in wind power generation by building a wind farm or to carry on with their previous activity. In order to invest, entrepreneurs in the wind energy sector must ask the politician for a permit and paying a bribe increases the probability of the permit being granted since the politician will put more effort in the bureaucratic process. The entrepreneurs bear some costs associated with bribing, such as the effort needed to keep the corrupted deal secret. These costs depend on institutional factors such as the level of social capital or the quality of law enforcement (e.g., the effort required to keep corruption secret negatively depends on the degree of social acceptance of bribing).

\footnotetext{
${ }^{4} \mathrm{~A}$ formal version of the model is available upon request.
} 
Once the entrepreneur obtains the permit, she can make the investment and build a wind farm. The return on investment depends on the revenues associated with the energy produced (increasing in the wind level) on one side, and on public incentives on the other. The public support incentive can either subsidize the building of the wind farm (irrespective of how much it generates) or remunerate the actual electricity generated, for example through feed in tariff or a tradable certificate system. A regime switch from the first to the second support scheme would make revenues more dependent on the wind level, and thus provide additional incentives to build in the windiest sites. The return on investment does not depend on the ability of the entrepreneur since the wind sector has traditionally been characterized by low levels of competition and revenues were mainly driven by public incentives.

Because we focus our attention on the first period of the establishment of wind power generation in Italy, we do not expect entrepreneurs to compete for permits. Whether a province will experience a corrupted wind market (e.g., all the entrepreneurs pay a bribe) depends on the quality of institutions and the wind level. In general the level of wind, which affects the returns on investment, leads economic agents to enter the wind energy market. In contexts where the institutional quality is low, the politician's intervention significantly increases the probability of obtaining permission and corruption is generally tolerated in the society, high wind will be correlated with a higher number of corrupted agents active in the wind energy market; if instead, without the direct intervention of the politician, the entrepreneur faces almost the same probability to get a permit and corruption is viewed poorly in the society, a high wind level is correlated with a higher number of honest agents active in the market. Thus, there is a complementarity between windiness and the quality of political institutions in determining the equilibrium level of corruption, such that considering two provinces with the same wind level but with a different probability of obtaining the permit via bribing, one should expect a higher level of corruption in the province characterized by worse institutions. On the other hand, comparing two provinces with similar institutional quality (and so similar chances of getting the permits using bribes) but with a different level of wind, one should expect more corruption in the high-wind province. The intuition is simple; since the marginal return to bribing is increasing in the wind level, we should expect a higher number of entrepreneurs entering in high-wind provinces and bribing the politician. The negative effect of windiness will be stronger in provinces characterized by a lower institutional quality. In the same way, a lower quality of institutions increases the number of corrupted entrepreneurs in the market, and it does so more in high-wind provinces that entail a larger marginal profit.

Another important implication of this framework is that the introduction of a market-based system in a context of poor institutions would lead to a greater increase in corruption in provinces characterized by a higher wind level. If higher amounts of public incentives increase the return to wind investments and lead a larger number of agents to enter the market, when the quality of institutions is low all the entrants pay a bribe in exchange for the permit and the level of corruption increases. Moreover, if the public incentive becomes more responsive to the actual energy generated (i.e. to the wind level), this effect becomes stronger in high wind provinces. Therefore, in the presence of poorly functioning institutions, a market based policy might actually have a larger negative impact, particularly where the greatest efficiency gains could be obtained, namely in provinces with the highest resource potential.

Note that an increase in the returns to bribing (due to a change in the wind level, the public policies or the quality of institutions), will increase the equilibrium level of corruption and, as a consequence, also the actual number of wind projects put in place. This is due to the fact that in this framework corruption helps to cut the red tape, eventually accelerating the development of the wind sector. Though in principle corruption can also hamper the development of an industry by imposing additional and unnecessary costs, the 
evidence accumulated in the official inquiries is consistent with the first hypothesis (see Sect. 3.1).

Having outlined the main factors which can fuel bribing in the emerging market of wind energy, we turn to our empirical exercise. We focus on the role of the wind level in determining corruption in a region characterized by weak institutions. Since the data cover a sufficiently long time period, we can analyze the effects of the transition between the two major policy regimes implemented to promote wind energy. The main predictions of the theory which we take to the data are the following:

(i) Ceteris paribus, the windiest provinces are more likely to experience corruption.

(ii) The increase in the remuneration of wind investments, due to the introduction of a market-based policy regime, leads to an increase in the extent of corruption, especially in high-wind provinces.

\section{Background and data}

\subsection{Wind power in Italy}

The incentives schemes to renewables, including wind power, began in 1992, when a feedin tariff known as CIP 6 was introduced to support renewables and "assimilated sources". 5 The feed-in tariff system managed to jump start investments which were important at a time of shortage of available power capacity, but also uncovered several flaws.

In order to overcome these pitfalls, and following the liberalization of the Italian electricity market, in 1999 a market-oriented mechanism based on tradable green certificates (known as "Certificati Verdi", CV) was implemented; this required power producers and importers to have a minimum share of electricity generated by renewable sources. The quota was set for the initial date of operation in 2001 at $2 \%$, gradually increasing over time (it is now $7 \%$ ). Green certificates can be exchanged on either the Italian electricity market or via bilateral contracts, and last for several years (12 and 15 years if issued before and after 2007 respectively). In the initial phase, an excess of demand pushed the prices of the green certificates up, from 99 Euro/ MWh in 2003 to 142.8 Euro/MWh in 2006. In addition to the CV incentives, revenues also accrue for electricity generation, thanks to priority dispatch to the electricity market or alternatively to the option of selling electricity at a minimum guaranteed price. The financial incentive regime for investment in renewables in Italy appears to be advantageous by international standards. The Italian energy authority has estimated the cost of the green certificate trade system at 400 million Euros in 2008 and at 1 billion in 2013. In addition, regional and provincial support schemes have also been put in place. The contribution of wind power has increased significantly after the introduction of the $\mathrm{CV}$ incentive system, and now contributes to almost $4 \%$ of the national electricity consumption. Virtually all the installed wind capacity is concentrated in the "Mezzogiorno", which hosts the largest wind potential (see Fig. 1 below).

The provinces of Foggia (FG), Benevento (BN) and Avellino (AV), which lie on the windy ridge of the south Appennines, host roughly one third of the whole national

\footnotetext{
5 The terminology has allowed several other sources, including thermal co-generation, to be included among the beneficiaries of the feed-in tariff, which has undermined the effectiveness of the policy in promoting traditionally renewable energy. Though the exclusion of "assimilated" sources from the incentives has been mandated in the European directive 2001/77/CE, a series of waivers have allowed this practice to persist to date.
} 


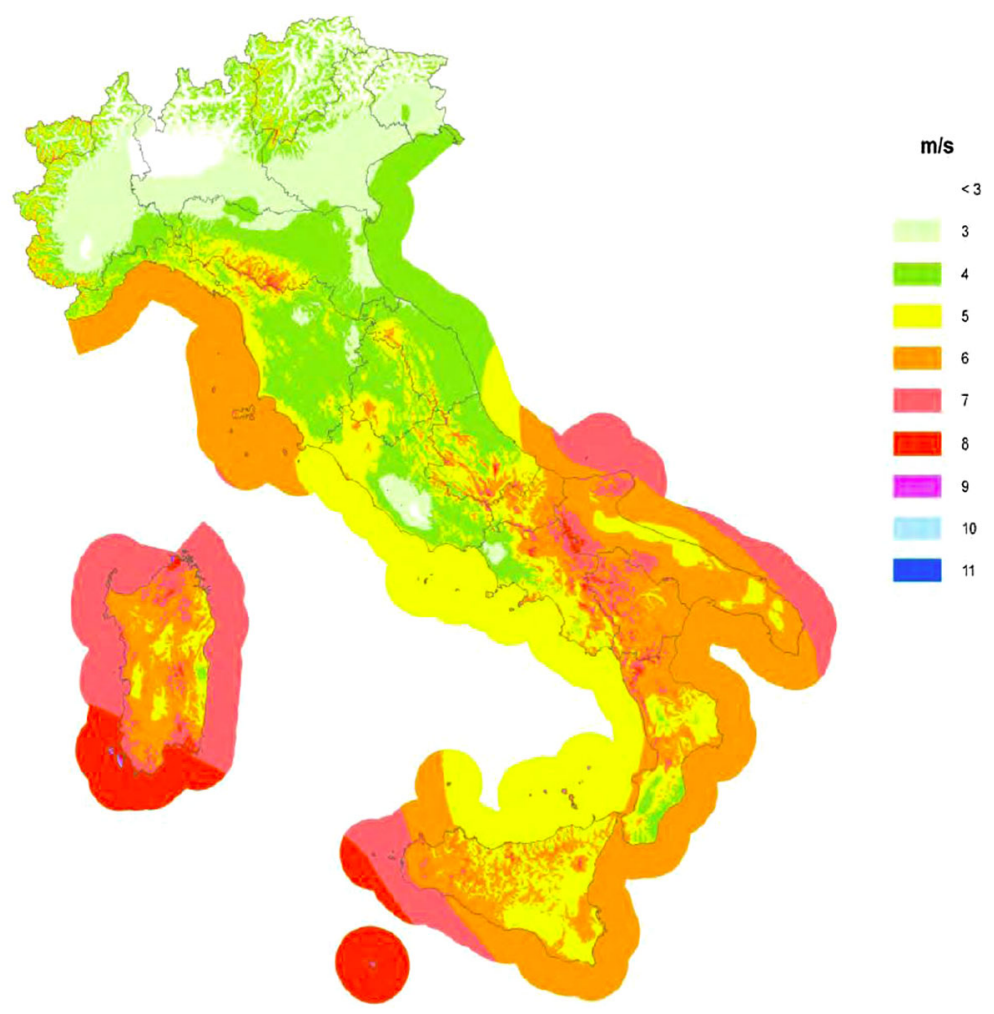

Fig. 1 Map of wind resources in Italy (speed at $75 \mathrm{~m}$ height). Source: CESI

capacity. These sites, together with the ones in Sardinia, were also the first to develop, and are characterized by higher utilization factors. More recently wind power has considerably expanded to several provinces of Sicily and Calabria.

Within the provinces, these rents are concentrated in a subset of municipalities, often of small size and located in areas with low population density. Thus, the royalties that the wind parks can yield to the local authorities (either legally or illicitly) - in exchange for the construction authorization - can be considerable, enough to induce corruption practices. Until 2010, there were no official guidelines on the rules for determining such royalties, and these were left to the discretion of local authorities, without any national harmonization. In addition, region-wide energy plans have been introduced quite slowly, allowing for a quite unregulated environment, which for example has only been partially able to account for other factors such as the integration with the electricity grids. Though the magnitude of the incentives is large, it is important to note that the wind sector still represents a small fraction of the overall economic output. The share of wind profits over the total value added of the economy does not exceed $2 \%$, even in the provinces most favorable to wind.

For the sake of our analysis, we assume that the regime change that the green certificate system brought about in 1999 (with effective use from 2001) can be considered the real turning point for policy. In the language of our model, this policy break has increased the return to wind investment and thus motivated more illicit activities. Although policies 
supporting renewables were present in the country even before the turn of the century, there are various reasons to support the idea that the green certificate system represented a significant and exogenous policy regime switch. First, the commitment to renewables of the European Union strengthened markedly around that time, culminating in the Renewable Energy Support (RES) directive which took effect in 2001 and set national indicative targets for renewable energy production from individual member states for the years 2010 and 2020. This increased the certainty of the policy support schemes for renewables, also providing a long term perspective in terms of quotas. Second, the liberalization of the Italian electricity market and the increased dynamics of the international energy markets, with oil prices starting to rise in 1999 and especially after 2001, provided an increased opportunity to enter a sector which was traditionally monopolistic. Finally, the wind turbine technology improved dramatically over time: the investment costs dropped considerably, from roughly 2000 to $1000 \mathrm{US} \$ / \mathrm{kW}$. The reliability of the technology also increased, as it became better suited to handle times of strong winds. Thus, the green certificate $(\mathrm{CV})$ system marked a clear change in terms of public support to the deployment of wind power, as testified by the marked increase in installed capacity post-2000.

The questions of interest for us are, (a) whether corruption practices have been fueled by the expectation of huge profits (due to public incentives) in windy provinces and consequently, (b) if there is a positive correlation between the development of the wind energy sector and corruption.

\subsection{Data description}

We use a panel dataset for the period 1990-2007 with annual observations on 34 provinces of Southern Italian regions. ${ }^{6}$ We make use of a data set compiled by the Italian National Institute of Statistics (ISTAT, "Statistiche Giudiziarie Penali") to measure criminal activity in the country. To compute the extent of corruption we use two measures: (a) criminal association activity (CrimAssoc), representing the number of "Criminal Association" offenses brought to justice by the five sectors of the police force, and (b) total criminal association (TCrimAssoc), the sum of offenses related to "Criminal Association" and "Mafia-related Criminal Association". Values are reported in terms of incidence per 100,000 inhabitants. Criminal association activity represents a very good measure of the level of corruption in the wind energy sector since, according to the Italian penal code, "it implies a sufficiently stable organization of two or more individuals who agree on committing illegal activities". This is exactly the case of the local bureaucrat which systematically exchanges authorizations for building wind farms for bribes from entrepreneurs. Actually most of the persons involved in corruption activity in the wind energy sector have been charged with this type of offense. ${ }^{7}$

The set of controls includes the log of real GDP per capita and the secondary school enrollment at the provincial level as provided by ISTAT. These controls are widely used in the crime literature and represent potential determinants of criminal behavior measuring the expected earning and cost opportunities. We also control for the population density in the province which is considered a key driver of the level of criminal activity (Glaeser and Sacerdote 1999). Finally we include the index of violent crime as a control to account for criminal attitudes in a given province. This is computed on the basis of the offenses

\footnotetext{
${ }^{6}$ For sake of comparison, Italian provinces are similar in size to US counties. During the period analyzed, six new provinces were instituted in the South of Italy. We disregard changes to the 1990 province classification, and attribute data on new provinces to those they originated from.

7 See the example reported in Sect. 1.
} 
Table 1 Descriptive Statistics

\begin{tabular}{|c|c|c|c|c|}
\hline Variables & Mean & Min & Max & Obs. \\
\hline Crim Assoc & $\begin{array}{l}2.277 \\
(1.775)\end{array}$ & 0 & 13.843 & 612 \\
\hline TCrim Assoc & $\begin{array}{l}3.034 \\
(2.342)\end{array}$ & 0 & 13.843 & 612 \\
\hline Violent crime Index & $\begin{array}{l}115.018 \\
(72.496)\end{array}$ & 14.017 & 558.863 & 612 \\
\hline Clear_Up & $\begin{array}{l}0.332 \\
(0.115)\end{array}$ & 0.094 & 0.721 & 476 \\
\hline Wind_Index & $\begin{array}{l}1.227 \\
(0.95)\end{array}$ & 0.211 & 3.469 & 612 \\
\hline Wind Plants & $\begin{array}{l}2.236 \\
(4.848)\end{array}$ & 0 & 44 & 612 \\
\hline Capacity (MW) & $\begin{array}{l}18.123 \\
(54.356)\end{array}$ & -0.6 & 642.17 & 612 \\
\hline GDP_pc (Log) & $\begin{array}{l}9.490 \\
(0.184)\end{array}$ & 8.941 & 10.134 & 612 \\
\hline School & $\begin{array}{l}0.814 \\
(0.12)\end{array}$ & 0.355 & 1.17 & 612 \\
\hline Population & $\begin{array}{l}609,323 \\
(54,4902.4)\end{array}$ & 89,043 & $3,117,095$ & 612 \\
\hline Pop_Density & $\begin{array}{l}176.778 \\
(299.849)\end{array}$ & 30.87 & 1881.168 & 612 \\
\hline
\end{tabular}

Standard deviations in parenthesis

brought to justice by the five sectors of the police force regarding the following crimes: massacre, homicide, infanticide, assault and battery, sexual assault, kidnapping, assassination attempt and theft. Table 1 below reports the descriptive statistics for all the variables.

The expected number of projects is proxied by the number of wind plants and the total capacity installed; for this purpose, since official statistics at the provincial level are only available from 2008 onwards, we rely on a dataset compiled by ANEV (National Association for Wind Energy). This covers the totality of wind parks and provides data on the location, capacity, size, year of initial operation, and ownership. Wind level is computed using data from the Italian Wind Atlas, which provides the average wind level per square kilometer for the whole Italian territory. ${ }^{8}$

In order to assign each province to a certain class of wind, we construct our own measure of windiness. We first consider the distribution of wind level (wind level per square kilometer) across the whole territory of the 34 provinces in our sample and we use the third quartile, or $5.2 \mathrm{~m} / \mathrm{s}$, as the threshold to define a one square kilometer area as high wind. Since the aim of our measure is to capture the attractiveness of the province for hosting wind parks, we take into account the percentage of the provincial area lying above that threshold while we give relatively less importance to the peaks in the distribution. The distribution of the quota of the provincial area lying above the $5.2 \mathrm{~m} / \mathrm{s}$ threshold is then used to identify the windiest provinces in the sample. For instance, the 8 windiest

\footnotetext{
${ }^{8}$ Wind speed is computed in meters per second $(\mathrm{m} / \mathrm{s})$ at $25 \mathrm{~m}$ above the sea level.
} 
provinces are the ones with more than $25 \%$ of their area above the $5.2 \mathrm{~m} / \mathrm{s}$ threshold, the following 9 windiest provinces have between 17 and $25 \%{ }^{9}$ of their area lying above the same threshold, and so on. The specific level of windiness that our measure assigns to each province corresponds to the quota of the provincial area lying above $5.2 \mathrm{~m} / \mathrm{s}$ multiplied by the average windiness above the same threshold. ${ }^{10}$

\subsection{Measurement issues}

A well known issue in crime-related literature is the problem of using counts of reported crimes. This can lead to the underestimation of the true number of committed crimes and bias the estimates if the explanatory variables of interest are correlated with the level of underreporting. In our case, the bias in reporting originates from the police investigative activity: criminal association is a difficult crime to detect as it usually does not involve a direct victim with an interest to report to the police. Rather, it is usually the police that report this type of offense to the judiciary after an investigation process. In this analysis our major concern is to measure criminal association levels rather than the extent of investigation activity by the police. Ehrlich (1996) extensively discussed the reporting bias in crime data and proposed several remedies. ${ }^{11}$ We use one of them, recently adopted by Fougere et al. (2009) and Bianchi et al. (2012), which consists of exploiting the panel structure of the data including time and province fixed effects. This method is very effective since it takes into account any systematic difference in police reporting activity between provinces (over time) or between different times (across provinces). We also include province specific time trends which allows for time varying, province specific bias in crime reporting by the police. Finally, we further address this issue presenting some descriptive evidence ${ }^{12}$ on the clear-up rate, a measure of the efficiency of police activity, which is defined as the ratio of crimes cleared up by the police over the total number of reported crimes.

\section{Methodology and results}

The main hypothesis we want to test is whether the presence of a renewable natural resource, namely wind energy, can favor the spread of corruption practices, especially in the presence of public policies such as subsidies increasing the expected returns of investments in wind energy. Given that profits in the Italian wind energy sector started to increase after the introduction of the green certificate (CV) system when significant public incentives were granted, we would expect an increase in corruption especially after that period. In turn, the increase in corruption should fuel the actual expansion of the wind energy sector.

\subsection{Suggestive evidence: corruption and wind energy development}

As a motivation for our analysis, we start by offering some descriptive evidence on the association between corruption activity and the actual expansion of the wind energy sector.

\footnotetext{
9 These percentage values represent respectively the second and the third quartile of the distribution of the quota of provincial area lying above the $5.2 \mathrm{~m} / \mathrm{s}$ threshold.

10 The figure reporting the distribution of the Wind Index across all the provinces in the sample is shown in Appendix 1.

11 See also Levitt (1996), Fougere et al. (2009) and Gould et al. (2002).

12 We cannot include this measure in the regressions since the data are only available until 2003.
} 
If the mechanism described above has actually been the one at work, we would expect to observe a larger expansion of the wind energy sector in provinces characterized by a higher level of criminal association activity. In addition, this effect should be stronger among the windiest provinces and after 1999, when the expected returns of the investment significantly increased. We measure the size of the wind energy sector with the total installed capacity and analyze whether the level of criminal association activity at time $t-1$ in province $i$, is correlated with the capacity (MW) installed in the same province at time $t$, and how this correlation varies for provinces with different wind levels. Given that corruption activity is associated with the authorized capacity but in the data we observe the actual capacity installed, we include the lagged value of criminal association since it is reasonable to assume at least a one year lag between authorization and installation. We estimate the following fixed effects model:

$$
\begin{aligned}
\text { Capacity }_{i, t}= & c+\alpha \text { Cap_Stock }_{i, t-1}+\beta \text { CrimAssoc }_{i, t-1}+\gamma \text { Inter }_{-} \text {CrimAssoc }_{i, t-1}+x_{i, t} \delta \\
& +\gamma_{i} \text { trend }_{i, t}+z_{i t}
\end{aligned}
$$

where Inter_CrimAssoc ${ }_{i, t-1}$ represents an interaction term between a post-1999 dummy (=1 for every year between 1999 and 2007), and the lagged value of criminal association activity. $z_{i t}$ represents the error term, which is $z_{i, t}=u_{i}+v_{t}+\epsilon_{i, t}$, where $u_{i}$ and $v_{t}$ are province and time effects, and $\epsilon_{i t}$ is an observation specific error. As a control, we have included the lagged stock of capacity installed in the province. Capacity can be influenced by its existing stock in two ways; on one hand our measure of capacity also accounts for the enlargement of an existing wind park, in terms of Megawatts added, therefore one would expect a positive correlation with the stock of capacity in the previous period. On the other hand, given the limited space available in a province for new plants, it is reasonable to assume that existing installations, both in terms of total capacity and total number of wind parks, influence negatively the installation of future ones. The vector of controls also includes GDP per capita and school enrollment, which account for the general level of socio-economic development of the province and the density of population which affects the space available for new wind energy installations.

The coefficients of interest are $\beta$ and $\gamma$; they illustrate whether criminal association activity is correlated with wind power installations and if the correlation becomes stronger after 1999, when the expected returns to wind energy started to increase and so did the attractiveness of the sector. We first estimate equation for all the provinces in the sample, then we repeat the estimation comparing the eight windiest provinces to the eleven neighboring provinces. In this case we perform a difference in difference exercise in which we compare the two groups of provinces before and after $1999^{13}$ and we evaluate whether the correlation between criminal association activity and wind power installations is stronger for the high-wind provinces of the treatment group than for the neighboring provinces of the control group. Table 2 reports the estimation results. ${ }^{14}$

In columns 1 and 2 we look at the simple correlation between the lagged value of criminal association and the capacity installed, considering all 34 provinces in the South

\footnotetext{
13 In this case we estimate a similar equation, but we interact the two variables of interest with a "treatment" dummy identifying the group of the eight windiest provinces.

${ }^{14}$ We only present the results for criminal association activity. Tables for total criminal association are available upon request.
} 
Table 2 Installed capacity and criminal association activity

\begin{tabular}{lllll}
\hline VARIABLES & $(1)$ & $(2)$ & $(3)$ & $(4)$ \\
& Capacity (MW) & Capacity (MW) & $\begin{array}{l}\text { Capacity (MW) } \\
\text { Capacity(MW) }\end{array}$ \\
\hline Stock_Capacity t-1 & 0.025 & 0.028 & 0.014 & 0.018 \\
Lag CrimAssoc & $(0.095)$ & $(0.096)$ & $(0.106)$ & $(0.108)$ \\
& $0.797^{*}$ & 0.263 & $2.381^{* *}$ & 0.542 \\
inter_CrimAssoc & $(0.462)$ & $(0.291)$ & $(1.067)$ & $(1.462)$ \\
& & $0.996^{*}$ & & $2.458^{* *}$ \\
Controls & & $(0.571)$ & & $(1.006)$ \\
Province and Year FE & Yes & Yes & Yes & Yes \\
Observations & 578 & Yes & Yes & Yes \\
R-squared & 0.497 & 578 & 323 & 323 \\
Number of prov_id & 34 & 0.500 & 0.525 & 0.258 \\
\hline
\end{tabular}

In first and second column, all 34 provinces of the South of Italy, in third and fourth column, provinces of the treatment and control groups only. inter_CrimAssoc is the interaction between the lagged value of criminal association activity (Lag CrimAssoc) and the dummy for the post-1999 period (1999-2007). Province specific time trends are included and clustered standard errors are in parenthesis. Control variables included are: School, log of GDP per capita, Population density and Violent crime Index.

Significance levels: *** $\mathrm{p}<0.01, * * \mathrm{p}<0.05, * \mathrm{p}<0.1$

region, while in columns 3 and 4 we compare the treatment group to the control group. In columns 1 and 3 only the lagged value of criminal association activity is included, while in columns 2 and 4, the baseline specification is enriched with an interaction term to account for the effect of the lagged value of criminal association in the post-1999 period.

In columns 1 and 3, the coefficient of the lagged value of criminal association is positive and significant in the baseline specification but becomes insignificant in columns 2 and 4, where the interaction Inter_CrimAssoc is always positive and significant. Notice that the size and significance of the coefficients of interest is much larger when we move to column 3 and 4, where we focus on the high wind provinces and compare them to the neighboring provinces. Results in Table 2 show that the positive correlation between the level of criminal association activity at time $t-1$, and the installed capacity at time $t$, is stronger in the high wind provinces of the treatment group, with a rise of this effect after 1999. This evidence is consistent with the predictions of the theoretical framework and documents the fact that the wind sector developed more in provinces with higher criminal association activity. In particular it suggests that, in high wind provinces where economic agents and bureaucrats, motivated by the high expected revenues, have been better "organized" and ready to engage in criminal association activity (resulting in more permits and concessions), the expansion of the wind energy sector has been higher.

It is very difficult to empirically analyze the association between criminal association activity and wind capacity installed, since there might be confounding factors affecting both corruption activity and the expansion of the wind energy sector. Though we partially address the problem of endogeneity by adding the lagged value of criminal association as an explanatory variable, including a full set of fixed effects as well as province specific time trends, and having a treatment group which is exogenously determined, this evidence should only be taken as suggestive. 


\subsection{Empirical analysis: wind resource and corruption}

The main purpose of the empirical exercise is to test whether there exists a causal relation between the presence of a renewable energy resource (i.e. wind) and the spread of corruption activity and that this relation becomes stronger after the introduction of the favorable policy regime in 1999. The exogenous variation in wind level across provinces is crucial to address our estimation in a robust way.

\subsubsection{Difference in difference: windy vs non windy provinces}

Assuming that all provinces are affected by the introduction of the policy in 1999 proportional to their wind level would be problematic since wind power plants are built only in provinces with a wind level above a certain threshold. Therefore only a subset of provinces can be considered to be affected by the policy. Accordingly, we employ a difference-indifference strategy (Angrist and Pischke 2009) in which we compare the eight windiest provinces $^{15}$ in the area of the South of Italy (treatment group) to the eleven neighboring provinces (control group). This is done to allow the comparison of two homogeneous groups of provinces. As mentioned above, in order to identify the windiest provinces we use a very accurate wind atlas and construct a measure of average windiness that takes into account the fraction of total provincial area lying above the third quartile of the wind resource distribution. The provinces in the treatment group have more than $25 \%$ of their area lying above the $5.2 \mathrm{~m} / \mathrm{s}$ threshold. The choice of the treatment group in the differencein-difference exercise is not an obvious one, since the wind threshold can be set at different levels. However, as already noted, there are a handful of provinces that host the greatest wind potential by far, and only very recently has this started to expand. In addition, since our analysis stops in 2007 , the restricted group of eight provinces is the most meaningful group to look at. The key assumption of the difference in difference strategy is that the outcome in the treatment group and in the control group would have followed the same time trend in the absence of the treatment (common trend assumption). ${ }^{16}$ It is generally very difficult to prove that the common trend assumption holds, but we are able to accomplish that both by providing some inspection and visualization of the behavior of the two groups of provinces and with the estimation exercise.

Figure 2 shows the average criminal association activity in the treated provinces compared to the control provinces. Since the beginning of the period the provinces of the control group experience a higher level of criminal association activity. Between 1990 and 1994 both the treatment and control provinces display a similar increasing trend, characterized by a peak around 1992-1994 when the treatment and the control group, experience a quite large and exceptional increase in criminal association activity, ${ }^{17}$ followed by a declining trend in both groups afterwards. Most importantly in 1997 the gap between the two groups begins to shrink and completely disappears around $2004 .^{18}$

\footnotetext{
15 Avellino, Benevento, Campobasso, Cosenza, Foggia, Potenza, Sassari, Trapani.

16 Notice that this does not imply that the two groups need to have the same mean of the outcome.

17 The increasing trend at the beginning of the nineties occurs in the whole Italian territory. In the period 1990-2003, criminal association activity at the provincial level in Italy increased on average by $3.9 \%$ per year, while between 1990 and 1993 the average annual increase was $22.3 \%$. Notice that this trend does not bias our diff-in-diff estimation as long as both the treatment and the control group experience it.

18 A similar pattern for total criminal association activity is shown in Appendix 1.
} 


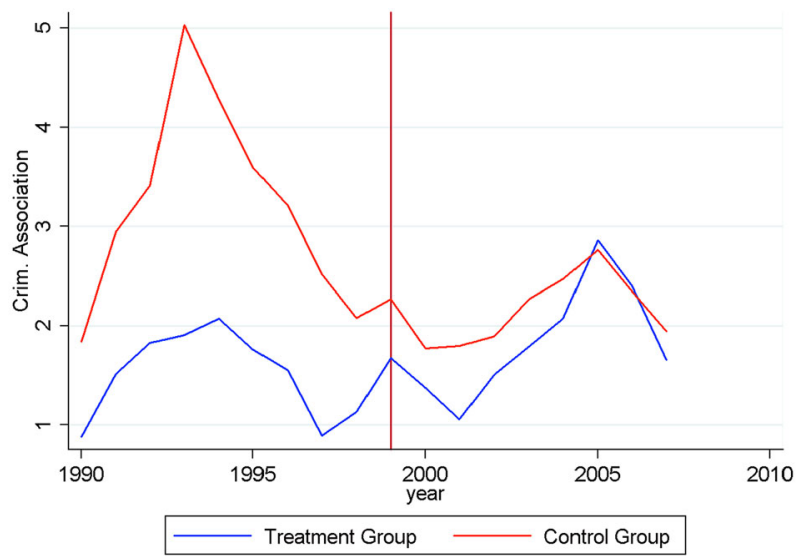

Fig. 2 Criminal association activity (number of offenses over 100,000 inhabitants). Treatment Group: Avellino, Benevento, Campobasso, Cosenza, Foggia, Potenza, Sassari, Trapani. Control Group: eleven neighboring provinces. Notice that in 1999 the tradable green certificates system ("Certificati Verdi", CV) was introduced

One might think that the reduction in the gap is due to a general diffusion of criminal activity in the treatment group. ${ }^{19}$ Figure 3 displays the pattern of the violent crime index in the treatment group compared to the control group. The difference with the previous graph is striking. The level of criminal activity in the control group remains larger than the one in the treatment group both in the pre- and post-period, and crucially there is no sign of a catching-up phenomenon. ${ }^{20}$

As expected, the windiest provinces have been characterized by a higher level of installed capacity relative to the control provinces in the whole period. ${ }^{21}$ The most significant acceleration occurred after 1999 and 2002, which provides further evidence of the structural break of the CV incentive scheme, which was established in 1999 and implemented in 2001.

Results in Table 3 are consistent with previous figures.

Control provinces display a significant higher level of criminal association activity compared to treated provinces before 1999, but the difference shrinks and becomes insignificant in the post treatment period. On the contrary, the difference in wind plants and capacity installed between the treatment and control provinces magnifies after 1999. In addition, control and treatment groups appear to be similar both before and after 1999, in other fundamentals, namely real GDP per capita, secondary school enrollment, population and crucially in the clear-up rate, which can be considered a measure of the efficiency of police activity. This evidence shows that the difference in difference strategy is valid since

\footnotetext{
19 In the robustness section we formally test this alternative explanation.

${ }^{20}$ Since the method of reporting offenses changed in 2004, in Appendix 1 we show the pattern of the ratio between the values in the control and treatment groups, for the three measures of criminal activity. The comparison is quite striking since we do not find the same decreasing pattern in the ratio of the violent crime index as in the two ratios of criminal association activity which are characterized by a visible declining trend, from roughly 2 in the first half of the 1990s (e.g., meaning that the control groups had twice as many charges per person) to parity in the latest years.

21 The figure displaying the development of the wind energy sector in the treated and control provinces, in terms of total capacity installed is reported in Appendix 1.
} 


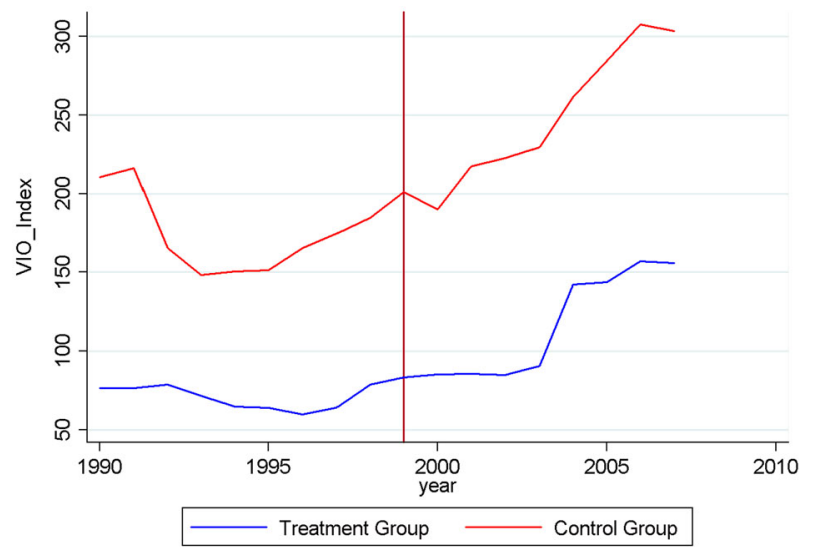

Fig. 3 Index of violent crime

we are comparing fundamentally similar provinces and rules out the possibility that our results are driven by an increase in police effort in the treated provinces vis-a-vis the control ones after 1999.

Turning to the estimation exercise, we use a specification similar to the one first implemented by Autor (2003), which includes leads and lags of the treatment dummy in the difference in difference model. In particular we add indicator variables equal to one for the treatment group in different time windows both before and after the treatment year. One might be concerned that criminal association activity started to increase in the treatment group (compared to the control group) before the treatment implying a violation of the common trend assumption. The inclusion of leads addresses this issue and allows us to test for the existence of pre-trends in the outcome. The inclusion of lags instead is useful to analyze how the treatment effect changes over time after the treatment. ${ }^{22}$ Let $T G$ denote the treatment group, then we estimate various specifications of the following equation:

$$
\operatorname{CrimAssoc}_{i, t}=c+\sum_{\tau=-m}^{-1} \alpha_{\tau} T G_{i, \tau}+\sum_{\tau=1}^{q} \alpha_{\tau} T G_{i, \tau}+\mathbf{x}_{i, t} \delta+\gamma_{i} \operatorname{trend}_{i, t}+u_{i}+v_{t}+\varepsilon_{i, t}
$$

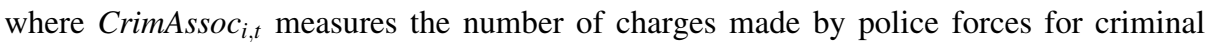
association offenses in province $i$ at time $t$. The variable of interest is $T G_{i, \tau}$, which is a dummy equal to one for the treated provinces in the time window $\tau$ and zero otherwise. ${ }^{23}$ Notice that we include $m$ time windows before 1999 and $q$ time windows from 1999 onwards, where $m$ and $q$ obviously depend on the length of the time windows. $\mathbf{x}_{i t}$ is a vector of control variables at the provincial level, namely log of the real GDP per capita, secondary school enrollment, population density in the province and the level of violent crime, trend $_{i, t}$ is a province specific trend which accounts for time varying unobservable factors, $u_{i}$ and $v_{t}$ are province and year fixed effects and $\epsilon_{i t}$ is an observation specific error term. Our empirical strategy is based on the identification assumption that there are no

22 This specification also accounts for the dynamics of returns to wind energy, our corruption-inducing variable, which experienced a significant increase after 1999, though largely fluctuating over the time period of analysis.

${ }^{23}$ In other words, $T G_{i, \tau}$ is an interaction term between the treatment group dummy and the time window $\tau$ dummy. 
Table 3 Balanced test

Treated provinces (mean)

(1)
Non-treated provinces (mean)

(2)
Mean difference (p value)

(3)

(A) Province characteristics
before 1999

\begin{tabular}{|c|c|c|c|}
\hline CrimAssoc & $\begin{array}{l}1.371 \\
(0.592)\end{array}$ & $\begin{array}{l}2.147 \\
(1.153)\end{array}$ & 0.155 \\
\hline TCrimAssoc & $\begin{array}{l}1.681 \\
(0.676)\end{array}$ & $\begin{array}{l}2.735 \\
(1.549)\end{array}$ & 0.04 \\
\hline Violent crime Index & $\begin{array}{l}64.571 \\
(18.274)\end{array}$ & $\begin{array}{l}117.773 \\
(71.954)\end{array}$ & 0.02 \\
\hline Clear_Up & $\begin{array}{l}0.343 \\
(0.121)\end{array}$ & $\begin{array}{l}0.357 \\
(0.108)\end{array}$ & 0.396 \\
\hline Wind_Index & $\begin{array}{l}2.742 \\
(0.584)\end{array}$ & $\begin{array}{l}1.04 \\
(0.408)\end{array}$ & 0 \\
\hline Wind Plants & $\begin{array}{l}2.937 \\
(2.363)\end{array}$ & $\begin{array}{l}0.136 \\
(0.258)\end{array}$ & 0 \\
\hline Capacity (MW) & $\begin{array}{l}9.942 \\
(15.184)\end{array}$ & $\begin{array}{l}0.351 \\
(0.826)\end{array}$ & 0.02 \\
\hline GDP_pc & $\begin{array}{l}9.463 \\
(0.126)\end{array}$ & $\begin{array}{l}9.399 \\
(0.113)\end{array}$ & 0.135 \\
\hline School & $\begin{array}{l}0.814 \\
(0.065)\end{array}$ & $\begin{array}{l}0.777 \\
(0.079)\end{array}$ & 0.151 \\
\hline Pop Density & $\begin{array}{l}91.525 \\
(33.148)\end{array}$ & $\begin{array}{l}289.723 \\
(532.213)\end{array}$ & 0.311 \\
\hline $\begin{array}{l}\text { Province characterist } \\
998\end{array}$ & & & \\
\hline CrimAssoc & $\begin{array}{l}1.896 \\
(1.394)\end{array}$ & $\begin{array}{l}1.962 \\
(0.838)\end{array}$ & 0.449 \\
\hline TCrimAssoc & $\begin{array}{l}2.355 \\
(1.392)\end{array}$ & $\begin{array}{l}2.587 \\
(1.126)\end{array}$ & 0.346 \\
\hline Violent crime Index & $\begin{array}{l}99.994 \\
(22.272)\end{array}$ & $\begin{array}{l}149.669 \\
(103.49)\end{array}$ & 0.101 \\
\hline Clear_Up & $\begin{array}{l}0.324 \\
(0.078)\end{array}$ & $\begin{array}{l}0.319 \\
(0.072)\end{array}$ & 0.442 \\
\hline Wind_Index & $\begin{array}{l}2.742 \\
(0.584)\end{array}$ & $\begin{array}{l}1.04 \\
(0.408)\end{array}$ & 0 \\
\hline Wind Plants & $\begin{array}{l}8.678 \\
(7.236)\end{array}$ & $\begin{array}{l}1.233 \\
(1.229)\end{array}$ & 0.001 \\
\hline Capacity (MW) & $\begin{array}{l}76.127 \\
(78.579)\end{array}$ & $\begin{array}{l}10.064 \\
(12.891)\end{array}$ & 0.006 \\
\hline GDP_pc & $\begin{array}{l}9.507 \\
(0.076)\end{array}$ & $\begin{array}{l}9.498 \\
(0.150)\end{array}$ & 0.438 \\
\hline School & $\begin{array}{l}0.907 \\
(0.042)\end{array}$ & $\begin{array}{l}0.874 \\
(0.072)\end{array}$ & 0.135 \\
\hline
\end{tabular}


Table 3 continued

\begin{tabular}{llll}
\hline & $\begin{array}{l}\text { Treated provinces } \\
(\text { mean }) \\
(1)\end{array}$ & $\begin{array}{l}\text { Non-treated provinces } \\
(\text { mean }) \\
(2)\end{array}$ & $\begin{array}{l}\text { Mean difference (p } \\
\text { value) } \\
(3)\end{array}$ \\
\hline Pop_Density & 90.401 & $\begin{array}{l}289.395 \\
(528.014)\end{array}$ & 0.152 \\
Obs. & $(32.598)$ & 11 & \\
\hline
\end{tabular}

Standard deviations in parentheses in columns (1) and (2)

unobservable factors correlated with both criminal association activity and the treatment group dummy. Formally, $\operatorname{Cov}\left(T G_{i, \tau}, \varepsilon_{i, t}\right)=0, \forall \tau$, must hold. However since the treatment group is determined according to the wind level, which is exogenous, and considering that we include province, year fixed effects and province specific time trends, it is difficult to imagine any unobservable factor correlated with both our dependent variable and the treatment group dummies.

In all specifications we use both clustered standard errors at the provincial level and bootstrapped (clustered) standard errors in order to deal with the relatively small number of clusters (19) and the potential presence of serial correlation in our dependent variables. We first run a specification of equation (a) that studies the trend of criminal association during the whole period and it is useful to rule out the presence of trends in our dependent variables before 1999. So we set $m, q=2$, and divide the entire period in four time windows of 4 years each. Then we focus only on the period post-1999, following the approval of the Green Certificate System (CV) and split it in two time windows of four years each $(m=0, q=2)$ and four time windows of two years each $(m=0, q=4)$ respectively. All these specifications are useful because they account for a gradual effect of the policy. Given our hypothesis, we expect the coefficients of interest, $\left\{\alpha_{\tau}\right\}$ with $\tau>0$ to be statistically higher than the coefficients $\left\{\alpha_{\tau}\right\}$ with $\tau<0$ and $\forall m, q$. For this purpose we present some tests of significance of the difference in the coefficients before and after 1999. In order to further address the problem of serial correlation which might affect the dependent variables, we make use of an additional specification to study the trend of our variables of interest in the treated provinces, as suggested by Bertrand et al. (2004). In particular, we take the average of all variables before and after 1999 and we estimate the following equation in a panel with a time dimension equal to two:

$$
\operatorname{CrimAssoc}_{i, t}=c+\alpha \operatorname{POST}_{i, 99-05}+\mathbf{x}_{i, t} \delta+u_{i}+v_{t}+\varepsilon_{i, t}
$$

where POST is a dummy equal to one for the treated provinces in the second period, and zero otherwise. To keep the before and after period sufficiently balanced, we restrict the sample to ten years (1995-2005), such that the averages correspond to the period 1995-1998 and 1999-2005, respectively. ${ }^{24}$

Turning to the estimation results, Table 4 reports estimates of equations (a) when setting $m, q=2$ and $m=0, q=2$, for criminal association activity in the first two columns, and for total criminal association activity in columns 3 and 4.

Results for criminal association activity show an increasing trend in our coefficient of interests belonging to $\left\{\alpha_{\tau}\right\}$ in equation (a), with two of them only marginally insignificant.

${ }^{24}$ The restriction to 10 years is done because our sample is characterized by large $\mathrm{T}$ and the serial correlation can be particularly severe in this case. Moreover and most importantly the precision of the Bertrand et al. (2004) method decreases with sample size. 
Table 4 Trend in simple and total criminal association in the whole period (1990-2007) for the 19 neighboring provinces

\begin{tabular}{|c|c|c|c|c|}
\hline VARIABLES & (1) CrimAssoc & (2) CrimAssoc & (3) TCrimAssoc & (4) TCrimAssoc \\
\hline \multirow{3}{*}{$\mathrm{TG}_{91 \_94}$} & 0.221 & & 0.690 & \\
\hline & $(0.601)$ & & $(0.712)$ & \\
\hline & $(0.638)$ & & $(0.824)$ & \\
\hline \multirow[t]{3}{*}{$\mathrm{TG}_{95 \_98}$} & 0.298 & & 0.853 & \\
\hline & $(0.689)$ & & $(0.707)$ & \\
\hline & $(0.871)$ & & (1.003) & \\
\hline \multirow[t]{3}{*}{$\mathrm{TG}_{99 \_02}$} & 1.266 & 0.892 & 2.094 & 1.030 \\
\hline & $(0.962)$ & $(0.415)^{* *}$ & $(1.078)^{*}$ & $(0.521)^{*}$ \\
\hline & (1.198) & $(0.440)^{*}$ & $(1.355)$ & $(0.491)^{* *}$ \\
\hline \multirow[t]{3}{*}{$\mathrm{TG}_{03 \_07}$} & 2.257 & 1.785 & 3.305 & 1.979 \\
\hline & $(1.265)^{*}$ & $(0.492)^{* * *}$ & $(1.539)^{* *}$ & $(0.688)^{* *}$ \\
\hline & $(1.631)$ & $(0.677)^{* *}$ & $(1.834)^{*}$ & $(0.781)^{* *}$ \\
\hline Controls & Yes & Yes & Yes & Yes \\
\hline Province and year FE & Yes & Yes & Yes & Yes \\
\hline Observations & 342 & 342 & 342 & 342 \\
\hline $\mathrm{R}^{2}$ & 0.325 & 0.325 & 0.303 & 0.301 \\
\hline Number of prov id & 19 & 19 & 19 & 19 \\
\hline
\end{tabular}

$\mathrm{TG}_{\mathrm{i}}$ is a dummy equal to 1 for the provinces in the treatment group for the period $\mathrm{i}$, and zero otherwise. All columns report FE estimates with the inclusion of province specific time trends. Clustered standard errors at the province level and clustered bootstrapped standard errors are in parenthesis. Control variables included are: School, log of GDP per capita, Population density and Violent crime Index

Significance levels: *** $\mathrm{p}<0.01, * * \mathrm{p}<0.05, * \mathrm{p}<0.1$

Table 5 Tests of the coefficients significance

\begin{tabular}{|c|c|c|c|}
\hline $\begin{array}{l}\text { Ho } \\
\text { CrimAssoc }\end{array}$ & $\mathrm{p}$ value & $\begin{array}{l}\text { Ho } \\
\text { TCrimAssoc }\end{array}$ & $\mathrm{p}$ value \\
\hline Cluster SE & & Cluster SE & \\
\hline $\mathrm{TG}_{91 \_94}=\mathrm{TG}_{95 \_98}$ & 0.8664 & $\mathrm{TG}_{91 \_94}=\mathrm{TG}_{95 \_98}$ & 0.7889 \\
\hline $\mathrm{TG}_{95 \_98}=\mathrm{TG}_{99} \_02$ & 0.0505 & $\mathrm{TG}_{95 \_98}=\mathrm{TG}_{99} \_02$ & 0.0503 \\
\hline $\mathrm{TG}_{95 \_98}=\left(\mathrm{TG}_{99 \_02}+\mathrm{TG}_{03 \_07}\right) / 2$ & 0.0123 & $\mathrm{TG}_{95 \_98}=\left(\mathrm{TG}_{99 \_02}+\mathrm{TG}_{03 \_07}\right) / 2$ & 0.0222 \\
\hline $\begin{array}{l}\left(\mathrm{TG}_{91 \_}{ }^{94}+\mathrm{TG}_{95} \_98\right) / 2=\left(\mathrm{TG}_{99} \_02\right. \\
\left.+\mathrm{TG}_{03 \_07}\right) / 2\end{array}$ & 0.0393 & $\begin{array}{l}\left(\mathrm{TG}_{91 \_94}+\mathrm{TG}_{95 \_98}\right) / 2= \\
\left(\mathrm{TG}_{99 \_02}+\mathrm{TG}_{03 \_07}\right) / 2\end{array}$ & 0.062 \\
\hline Bootstrapped SE & & Bootstrapped SE & \\
\hline $\mathrm{TG}_{91 \_94}=\mathrm{TG}_{95 \_98}$ & 0.8808 & $\mathrm{TG}_{91 \_94}=\mathrm{TG}_{95 \_98}$ & 0.7734 \\
\hline $\mathrm{TG}_{95 \_98}=\mathrm{TG}_{99 \_02}$ & 0.0577 & $\mathrm{TG}_{95 \_98}=\mathrm{TG}_{99 \_02}$ & 0.0288 \\
\hline $\mathrm{TG}_{95 \_98}=\left(\mathrm{TG}_{99 \_02}+\mathrm{TG}_{0307}\right) / 2$ & 0.0316 & $\mathrm{TG}_{95 \_98}=\left(\mathrm{TG}_{99 \_02}+\mathrm{TG}_{03 \_07}\right) / 2$ & 0.0161 \\
\hline $\begin{array}{c}\left(\mathrm{TG}_{91 \_94}+\mathrm{TG}_{95 \_98}\right) / 2= \\
\left(\mathrm{TG}_{99 \_02}+\mathrm{TG}_{03 \_07} / 2\right.\end{array}$ & 0.0814 & $\begin{array}{c}\left(\mathrm{TG}_{91} \_94+\mathrm{TG}_{95} \_98\right) / 2= \\
\left(\mathrm{TG}_{99 \_02}+\mathrm{TG}_{03 \_07}\right) / 2\end{array}$ & 0.0454 \\
\hline
\end{tabular}

Column 3 displays a similar trend for total criminal association activity, but we find positive and also significant coefficients associated to the 1999-2002 and 2003-2007 periods. In Table 5 we report the test of significance of the difference of the coefficients 


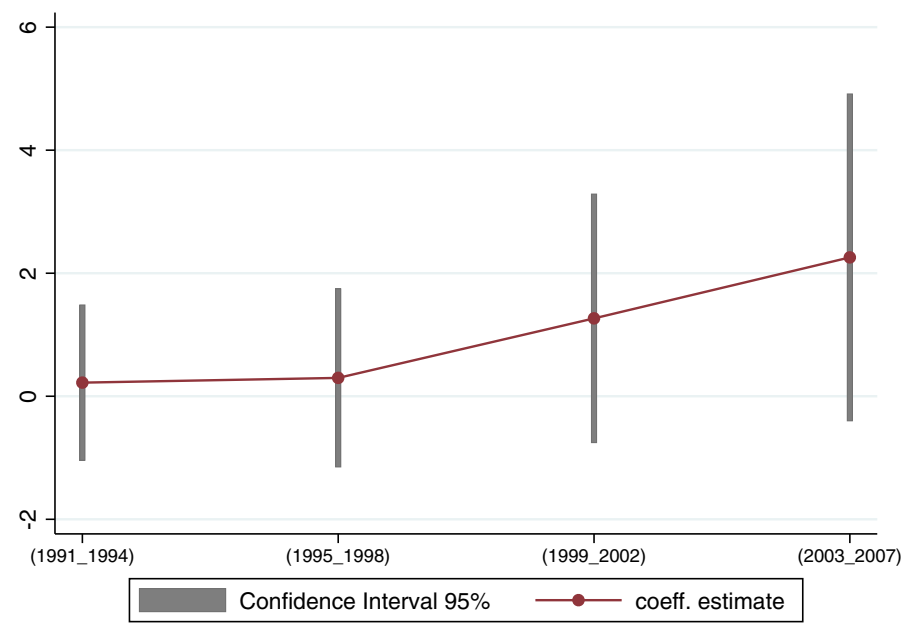

Fig. 4 Estimated impact of the introduction of the green certificate system on the level of criminal association activity in the treatment group for the years before, during and after 1999. Vertical bands represent \pm 1.96 times the standard error of each point estimate

before and after 1999. The results clearly show no evidence of a pre-trend in our dependent variables; the increase in both simple and total criminal association activity occurred in the treatment compared to the control group appears to become positive only in the post-1999 period. Figure 4 illustrates the pattern of the coefficients in column 1.

The estimation results for the specification of equation (a) in which we only focus on the post-1999 period are shown in columns 2 and 4 of Table 4; for both measures of criminal association activity, all coefficients of interest belonging to $\left\{\alpha_{\tau}\right\}_{\tau>0}$ are positive and significant.

Columns 1 and 3 of Table 6 report the results for equation (a), where the post-1999 period is divided into four time windows $(q=4)$; for both dependent variables, the coefficients increase over time in significance and magnitude. In particular, from column 1 , it is evident that the treatment group experiences a progressively higher increase in criminal association activity compared to the control group. Columns 2 and 4 display the results for equation (b). Recall that we collapse the panel in two time periods (1995-1998, 1999-2007), a method suggested by Bertrand et al. (2004) which represents a simple remedy if variables of interest are serially correlated.

Note that $\alpha$, the coefficient of interest, is significant both for total criminal association and for criminal association. As described in the theoretical framework, corruption is driven by the revenues in the wind energy sector. Although the revenues increase substantially after 1999, their trend oscillates over time both before and after 1999, therefore the specifications with the time windows are the most appropriate to be used here. However looking at longer time periods is a very effective way to provide a synthetic description of the reality. The size of the effect which we find is remarkable; after the introduction of a green certificate system high wind provinces experienced on average an increase of $\approx 0.9$ (per 100000 inhabit.) of association activity crimes $(\approx 1$ for the total criminal association activity) compared to the neighboring provinces. This is very sizable given that the average crime level in the sample is of about 2 (per 100,000 inhabit.). It might seem surprising that such large effect on province wide corruption has been driven by a sector, which represents 
Table 6 Trend in simple and total criminal association after the introduction of the green certificate system (1999-2007) for the 19 neighboring provinces

\begin{tabular}{|c|c|c|c|c|}
\hline VARIABLES & (1) CrimAssoc & (2) CrimAssoc & (3) TCrimAssoc & (4) TCrimAssoc \\
\hline \multirow[t]{3}{*}{$\mathrm{TG}_{99 \_00}$} & 0.980 & & 0.937 & \\
\hline & $(0.548)^{*}$ & & $(0.643)$ & \\
\hline & $(0.519)^{*}$ & & $(0.568)^{*}$ & \\
\hline \multirow[t]{3}{*}{$\mathrm{TG}_{01 \_02}$} & 1.005 & & 1.152 & \\
\hline & $(0.435)^{* *}$ & & $(0.552)^{*}$ & \\
\hline & $(0.604)^{*}$ & & $(0.694)^{*}$ & \\
\hline \multirow[t]{3}{*}{$\mathrm{TG}_{03 \_04}$} & 1.730 & & 2.063 & \\
\hline & $(0.473)^{* * *}$ & & $(0.630)^{* * *}$ & \\
\hline & $(0.703)^{* *}$ & & $(0.806) * *$ & \\
\hline \multirow[t]{3}{*}{$\mathrm{TG}_{05 \_07}$} & 2.098 & & 1.964 & \\
\hline & $(0.776)^{* *}$ & & $(0.992)^{*}$ & \\
\hline & $(0.988)^{* *}$ & & $(1.097)^{*}$ & \\
\hline \multirow[t]{2}{*}{$\mathrm{POST}_{99 \_05}$} & & $0.867 * *$ & & $0.997 * *$ \\
\hline & & $(0.356)$ & & $(0.394)$ \\
\hline Controls & Yes & Yes & Yes & Yes \\
\hline Province and year FE & Yes & Yes & Yes & Yes \\
\hline Observations & 342 & 38 & 342 & 38 \\
\hline $\mathrm{R}^{2}$ & 0.326 & 0.522 & 0.301 & 0.450 \\
\hline Number of prov_id & 19 & 19 & 19 & 19 \\
\hline
\end{tabular}

$\mathrm{TG}_{\mathrm{i}}$ is a dummy equal to 1 for the provinces in the treatment group for the period $\mathrm{i}$, and zero otherwise. In first and third column, FE regressions with province specific time-trends. Clustered standard errors at the province level and clustered bootstrapped standard errors are in parenthesis. In second and fourth column, panel collapsed in two periods as in Bertrand et al. (2004). $\mathrm{POST}_{\mathrm{i}}$ is a dummy equal to 1 for the provinces in the treatment group in the post-1999 period and zero otherwise. Control variables included are: School, log of GDP per capita, Population density and Violent crime Index

Significance levels: $* * * \mathrm{p}<0.01, * * \mathrm{p}<0.05, * \mathrm{p}<0.1$

only a small share of the local economy. However the implementation of a wind farm involves a large number of people, who can potentially be corrupted. ${ }^{25}$ Therefore in reality each wind project can be associated with a relatively large number of corruption charges.

All in all, the empirical results in this section are consistent with the predictions of the theory, suggesting that after 1999 the windiest provinces experienced a significant increase in both measures of criminal association activity, compared to the neighboring control provinces. In an area characterized by weak socio-political institutions, the introduction of the new and more favorable policy regime system had a strong negative effect (in terms of corruption), especially in the provinces with the highest potential for efficiency gains.

\subsubsection{Robustness}

Despite a set of strong empirical results, at this stage we cannot completely rule out the presence of an omitted variables bias. In particular, the trend in criminal association activity we observe in the treatment group might be due to a spillover effect from the

${ }^{25}$ In the theoretical framework we just assume one bureaucrat and one entrepreneur for the sake of simplicity. 
neighboring provinces. In the next three sections we provide robustness analysis to address this issue.

\subsubsection{Catching-up between treatment and control? Following Gennaioli and Onorato} (2010), we change our measure of criminal activity to understand whether we are merely capturing a general diffusion of criminal behavior which does not depend on the expectation of rents in the wind energy sector.

For this purpose we re-estimate equations (a) and (b), changing our dependent variable with the index of violent crime. Results in Table 7 indicate that in all specifications the coefficients of interest are insignificant and eventually negative, showing a similar trend of the violent crime index in the treated provinces compared to the control provinces. Another potential explanation for our results could be that the treatment areas are simply absorbing criminal activity away from the other provinces because of the increment of economic activity that may ensue government intervention. To rule out this channel we correct the main specifications by allowing GDP, schooling and population density to interact with treatment dummies. In Table 8 we show that our results are robust to the inclusion of these interaction terms. ${ }^{26}$

Overall this evidence allows us to reject with confidence the "spillover effect" or "catching-up" explanation, suggesting that in the period under consideration, the treatment group did not experience a general increase in criminal activity.

4.2.2.2 Using the actual wind measure As noticed above, our results might merely capture the impact of other factors characterizing the treatment group. To address this issue we repeat the estimation of specifications (a) and (b) considering the actual level of our index of windiness; in particular, we allow for different treatment intensities interacting $T G_{i}$ with the value of the wind index in province $i$, and now use $T G_{-} W_{i n d}$ to run the same set of regressions. In this case our identification assumption implies $\operatorname{Cov}\left(T G_{-} \operatorname{Wind}_{i,(\tau)}, \varepsilon_{i, t}\right)=0, \forall \tau$. In Appendix 2 we report the results of this additional specification. Results are consistent with those in Tables 4, 5 and 6, and we find the effects to be even stronger. These findings provide us with sufficient confidence that we are correctly identifying the impact of the wind level of our treatment group.

4.2.2.3 Different treatment and control We perform a number of additional checks ${ }^{27}$ to show the robustness of our findings changing the treatment group. The first test consists of changing the treatment group as a whole. In this case the results should disappear. As an alternative treatment group we consider the eight least windy provinces, which are compared with our original control group. The trends in criminal association activity of these two groups of provinces do not display any significant difference, which demonstrates that our results are not driven by unobservable features characterizing the control group. Then we check whether our results remain valid when we try other cutoffs for the wind index to select the treatment group. We start dropping Cosenza from the treatment group since this province displays a level of wind more similar to the provinces belonging to the third quartile of the wind measure ${ }^{28}$ and our findings remain valid. As a third check we consider

\footnotetext{
26 The corresponding tests of significance are reported in Appendix 2.

27 All the results described in this section are available upon request.

28 This is evident from the figure of the wind distribution reported in Appendix 1.
} 
Table 7 Trend in Violent Crime Index in the whole period (1990-2007) for the 19 neighboring provinces

\begin{tabular}{|c|c|c|}
\hline Variables & $\begin{array}{l}(1) \\
\text { Violent } \\
\text { crime index }\end{array}$ & $\begin{array}{l}(2) \\
\text { Violent } \\
\text { crime ir }\end{array}$ \\
\hline $\mathrm{TG}_{91 \_94}$ & $\begin{array}{l}0.106 \\
(0.144) \\
(0.175)\end{array}$ & \\
\hline $\mathrm{TG}_{95 \_98}$ & $\begin{array}{l}-0.006 \\
(0.168) \\
(0.208)\end{array}$ & \\
\hline $\mathrm{TG}_{99 \_02}$ & $\begin{array}{l}-0.053 \\
(0.226) \\
(0.273)\end{array}$ & $\begin{array}{l}-0.037 \\
(0.095) \\
(0.101)\end{array}$ \\
\hline $\mathrm{TG}_{03 \_07}$ & $\begin{array}{l}-0.175 \\
(0.253) \\
(0.356)\end{array}$ & $\begin{array}{l}-0.118 \\
(0.179) \\
(0.147)\end{array}$ \\
\hline
\end{tabular}

TG99_00

$-0.032$

(0.104)

(0.106)

$\mathrm{TG}_{01 \_02}$

0.011

(0.141)

$\mathrm{TG}_{03 \_04}$

$-0.116$

(0.181)

(0.161)

$-0.043$

(0.284)

(0.185)

POST $_{99 \_05}$

Controls

Yes

Yes

Yes

Province and year FE

Yes

Yes

Observations

342

$\mathrm{R}^{2}$

0.804

342

Yes

Yes

Yes

38

Number of prov_id

19

0.803

0.614

$\mathrm{TG}_{\mathrm{i}}$ is a dummy equal to one for each province in the treatment group in the period $\mathrm{i}$, and zero otherwise. In columns (1)-(3), OLS regressions with time, province fixed effects, province specific time trends and clustered standard errors at the province level (in parenthesis). In fourth column, panel collapsed in two periods as in Bertrand et al. (2004). POST $_{\mathrm{i}}$ is a dummy equal to 1 for the provinces in the treatment group in the post-1999 period and zero otherwise. Control variables included are: School, log of GDP per capita and Population density Significance levels: *** $\mathrm{p}<0.01, * * \mathrm{p}<0.05, * \mathrm{p}<0.1$

a larger treatment group, adding the next two windiest provinces. ${ }^{29}$ As expected in this case the findings are attenuated. To ensure that our results are not driven by the behavior of a particular province, we repeat our estimation exercise dropping from the treatment group

29 Agrigento, Nuoro. 
Table 8 Trend in simple and total criminal association in the whole period (1990-2007) for the 19 neighboring provinces when the interaction terms between GDP, Population, Schooling and the treatment dummy are included

\begin{tabular}{|c|c|c|c|c|}
\hline VARIABLES & (1) CrimAssoc & (2) CrimAssoc & (3) TCrimAssoc & (4) TCrimAssoc \\
\hline \multirow[t]{3}{*}{$\mathrm{TG}_{91 \_94}$} & -0.044 & & 0.591 & \\
\hline & $(0.578)$ & & $(0.656)$ & \\
\hline & $(0.692)$ & & $(0.880)$ & \\
\hline \multirow[t]{3}{*}{$\mathrm{TG}_{95 \_98}$} & -0.091 & & 0.669 & \\
\hline & $(0.748)$ & & $(0.813)$ & \\
\hline & $(0.961)$ & & (1.114) & \\
\hline \multirow[t]{3}{*}{$\mathrm{TG}_{99 \_02}$} & 0.725 & 0.833 & 1.614 & 0.832 \\
\hline & $(0.985)$ & $(0.418)^{*}$ & $(1.160)$ & $(0.487)$ \\
\hline & $(1.216)$ & $(0.547)$ & $(1.425)$ & $(0.604)$ \\
\hline \multirow[t]{3}{*}{$\mathrm{TG}_{03 \_07}$} & 1.709 & 1.850 & 2.869 & 1.922 \\
\hline & $(1.326)$ & $(0.456) * * *$ & $(1.622)^{*}$ & $(0.647)^{* * *}$ \\
\hline & $(1.671)$ & $(0.736)^{* *}$ & $(1.899)$ & $(0.836)^{* *}$ \\
\hline \multirow[t]{3}{*}{ GDP_TG } & -1.547 & -1.535 & -0.700 & -1.235 \\
\hline & $(1.763)$ & (1.926) & $(2.126)$ & $(2.516)$ \\
\hline & $(2.263)$ & $(2.021)$ & $(2.467)$ & $(2.306)$ \\
\hline \multirow[t]{3}{*}{ PopDens_TG } & -0.091 & -0.095 & -0.217 & -0.195 \\
\hline & $(0.141)$ & $(0.130)$ & $(0.109)^{*}$ & $(0.098)^{*}$ \\
\hline & $(0.207)$ & $(0.189)$ & $(0.214)$ & $(0.202)$ \\
\hline \multirow[t]{3}{*}{ Sch TG } & 7.595 & 7.360 & 7.076 & 8.436 \\
\hline & $(5.271)$ & $(4.896)$ & $(6.277)$ & $(5.730)$ \\
\hline & $(6.619)$ & $(6.012)$ & $(6.970)$ & $(6.230)$ \\
\hline Controls & Yes & Yes & Yes & Yes \\
\hline Province and year FE & Yes & Yes & Yes & Yes \\
\hline Observations & 342 & 342 & 342 & 342 \\
\hline $\mathrm{R}^{2}$ & 0.330 & 0.330 & 0.309 & 0.308 \\
\hline Number of prov_id & 19 & 19 & 19 & 19 \\
\hline
\end{tabular}

$\mathrm{TG}_{\mathrm{i}}$ is a dummy equal to 1 for the provinces in the treatment group for the period $\mathrm{i}$, and zero otherwise. $\mathrm{FE}$ regressions with province specific time-trends. Clustered standard errors at the province level and clustered bootstrapped standard errors are in parenthesis. Control variables included are: School, log of GDP per capita, Population density and Violent crime Index

Significance levels: *** $\mathrm{p}<0.01, * * \mathrm{p}<0.05, * \mathrm{p}<0.1$

each province at a time. Despite weakening in some cases, as when we drop the windiest province, Potenza, our results remain robust. During the period under consideration, four provinces in our sample experienced a secession leading to the creation of six new provinces. We have attributed the data on new provinces to the ones they originated from to keep the time series consistent. However one might be concerned that we are disregarding potential institutional changes taking place after a secession. ${ }^{30}$ To address this issue we drop the four provinces that experienced a secession and the results are still valid. ${ }^{31}$. As a

\footnotetext{
30 We believe this problem might arise only for two of the six new provinces. In fact four of them were created only in 2005, at the end of the period under consideration.

31 We wish to thank an anonymous referee for suggesting this check
} 
last check we enlarge the control group and we compare our original treatment group with all the other twenty six provinces of the South of Italy. Results remain strong and significant also in this case.

\section{Conclusions}

Recent anecdotal evidence suggests the diffusion of corruption practices in the renewable energy sector. In Italy, several inquiries have looked into corrupt practices and bribes conceived with the aim of building wind farms and appropriating the associated public support. This paper has analyzed the link between public subsidies for renewable energy and the potential scope for rent seeking and corruption. To our knowledge, this is the first attempt to study whether public incentives to renewable energy resources could lead to an increase in illegal activities. This is a highly policy relevant topic since over the past years several countries implemented public support policies meant to promote renewables, which are now being evaluated.

Using a simple model of corruption, we show that in a context of weak institutions windier provinces are more likely to experience corruption, especially after the introduction of a more favorable policy regime. Moreover, the number of wind energy projects in a given province is expected to increase with the extent of corruption. We test these results using Italian data at the provincial level for the period 1990-2007, and we find strong empirical evidence that supports the theory, establishing that in the presence of poor institutions, public policy can fuel corruption. The main finding is that criminal association activity increased more in high-wind provinces and especially after the introduction of a favorable market-based regime of public incentives.

Overall, the paper points out that even well designed policies can have an adverse impact in heavily regulated environments with poorly functioning socio-political institutions, especially in places with the highest potential for efficiency gains. The magnitude of our empirical estimates is significant: for an average wind park (of $10 \mathrm{MW}$ ) installed after 1999, and which receives about 1.5 Million euro per year in public support, the number of criminal association offenses has increased by $6 \%$ in the high-wind provinces with respect to the less windy ones. ${ }^{32}$ These results draw clear normative implications, particularly for countries which are characterized by abundant renewable resources and by weak institutions.

Besides establishing a clear link between renewable energy subsidies and corruption, our paper does not allow to quantify additional welfare impacts. From the very rapid expansion of wind power installations in Southern Italy one can presume that corruption has helped cut through the red tape, rather than having reduced the equilibrium provision under the optimum. There could also be corruption-induced welfare costs which we do not consider, such as entrepreneurs using "preferred" suppliers of potentially lower quality building materials, though that would constitute a small share of investment costs compared to the actual wind turbine. However, given the relatively small share of renewable energy in the economy, the largest impacts of public subsidies on economic development are likely to happen through increased corruption, which we have shown to be significant.

Since this analysis has been tested on the case of wind power, the results of our study cannot be generalized to other types of renewables, such as solar or hydropower. In

32 This number comes from back-of-the-envelope calculations based on the coefficient of the specification $a$ la Bertrand et al. (2004). 
principle, it could be the case that wind energy, being capital intensive, naturally leads to oligopolistic markets, where the establishment of connections between few entrepreneurs and local bureaucrats is easier. Furthermore, when compared to solar, the authorization process is more difficult, since wind farms necessitate vast areas and generally have a bigger environmental impact. As a consequence, local politicians have more discretionary power and the room for corruption is larger. Our research agenda comprises the study of other types of renewable resources to address this set of issues. In general, assessing the role of political economy for the case of renewable energy is a fruitful area for future research since several issues remain unexplored, and at the same time renewable energy it is becoming a relevant sector of the economy whose efficient control demands an in-depth analysis of all the main economic incentives at play.

Acknowledgments The authors are grateful to Antoine Dechezlepretre, Roberta Distante, Vincenzo Galasso, Reyer Gerlagh, Humberto Llavador, Tommaso Nannicini, Gaia Narciso, Marcella Nicolini, Jesse Shapiro, Mirco Tonin, and audience at IMT, Lucca, LSE, Oxford, Stanford, the 1st workshop on organized crime at Cattolica University, the 9th EEM conference at EUI, Florence,the 19th EAERE conference in Prague and the Cesifo Summer Institute in Venice for very helpful comments. We also thank Bryan Vadheim for editorial assistance. The research leading to these results has received funding from the European Community's Seventh Framework Program FP7/2007-2013 under Grant agreement number 282846 (LIMITS) and from the UK Economic and Social Research Council through the Centre for Climate Change Economics and Policy.

Open Access This article is distributed under the terms of the Creative Commons Attribution 4.0 International License (http://creativecommons.org/licenses/by/4.0/), which permits unrestricted use, distribution, and reproduction in any medium, provided you give appropriate credit to the original author(s) and the source, provide a link to the Creative Commons license, and indicate if changes were made.

\section{Appendix 1}

See Figs. 5, 6, and 7 and 8.

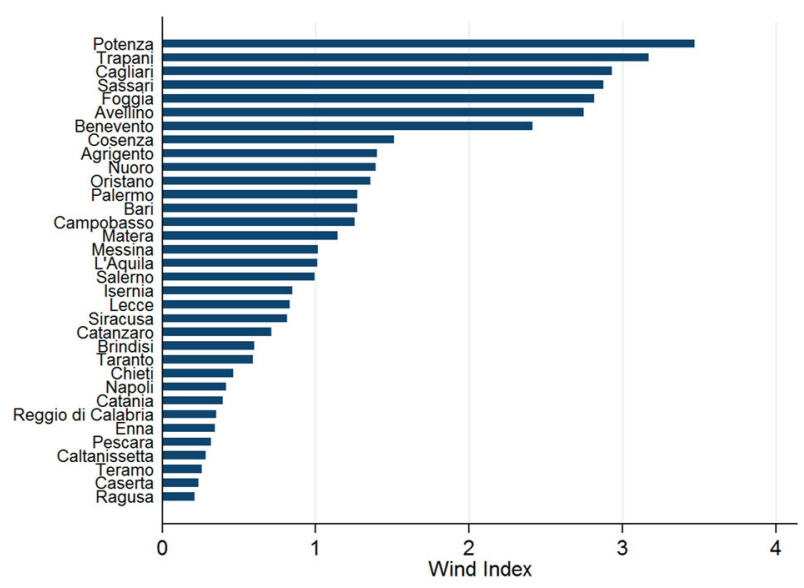

Fig. 5 Distribution of the wind index 


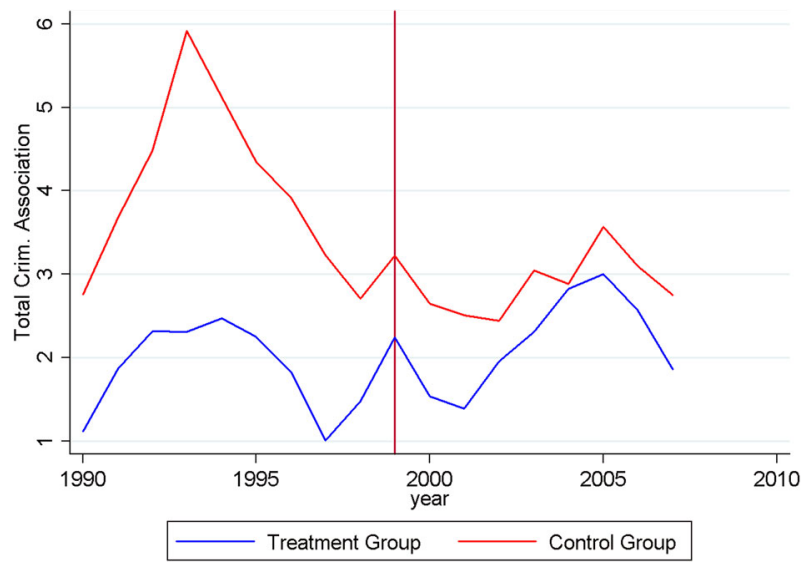

Fig. 6 Total criminal association activity (number of offences over 100,000 inhabitants)

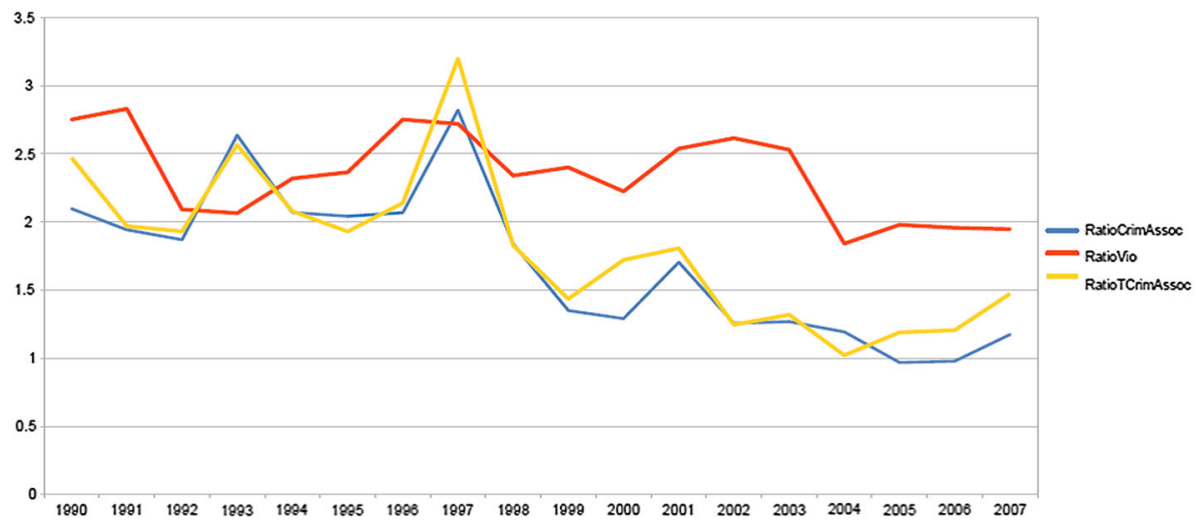

Fig. 7 Ratios between the level of both measures of criminal association activity and Index of Violent Crime in the control and treated provinces. Treatment Group: Avellino, Benevento, Campobasso, Cosenza, Foggia, Potenza, Sassari, Trapani. Control Group: eleven neighbouring provinces. Notice that in 1999, tradable green certificates system ("Certificati Verdi", CV) was introduced. VioIndex is the index of violent crime, while CrimAssoc denotes Criminal Association activity and TCrimAssoc denotes Total Criminal Association activity (sum of simple criminal association and criminal association of Mafia type). 


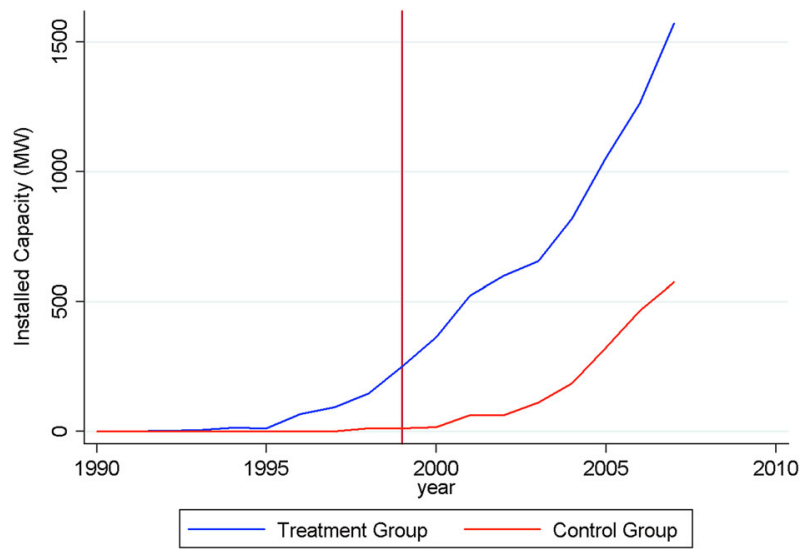

Fig. 8 Installed capacity (MegaWatt)

\section{Appendix 2: Robustness}

See Tables 9, 10, 11 and 12 .

Table 9 Test of the Coefficients provinces when the interaction terms between GDP, Population, Schooling and the treatment dummy are included (Sample: 19 provinces)

\begin{tabular}{|c|c|c|c|}
\hline $\begin{array}{l}\mathrm{H}_{0} \\
\text { CrimAssoc }\end{array}$ & $\begin{array}{l}P \\
\text { value }\end{array}$ & $\begin{array}{l}\mathrm{H}_{0} \\
\text { TCrimAssoc }\end{array}$ & $\begin{array}{l}P \\
\text { value }\end{array}$ \\
\hline Cluster SE & & Cluster SE & \\
\hline $\mathrm{TG}_{91 \_94}=\mathrm{TG}_{95 \_98}$ & 0.918 & $\mathrm{TG}_{91 \_94}=\mathrm{TG}_{95 \_98}$ & 0.899 \\
\hline $\mathrm{TG}_{95 \_98}=\mathrm{TG}_{99 \_02}$ & 0.084 & $\mathrm{TG}_{95 \_98}=\mathrm{TG}_{99 \_02}$ & 0.102 \\
\hline $\mathrm{TG}_{95 \_98}=\left(\mathrm{TG}_{99 \_02}+\mathrm{TG}_{03 \_07}\right) / 2$ & 0.018 & $\mathrm{TG}_{95 \_98}=\left(\mathrm{TG}_{99 \_02}+\mathrm{TG}_{03 \_07}\right) / 2$ & 0.037 \\
\hline $\begin{array}{l}\left(\mathrm{TG}_{91} \_94+\mathrm{TG}_{95} \_98\right) / \\
2=\left(\mathrm{TG}_{99 \_02}+\mathrm{TG}_{03 \_07}\right) / 2\end{array}$ & 0.064 & $\begin{array}{l}\left(\mathrm{TG}_{91} \_94+\mathrm{TG}_{95 \_98}\right) / \\
2=\left(\mathrm{TG}_{99 \_02}+\mathrm{TG}_{03 \_07}\right) / 2\end{array}$ & 0.104 \\
\hline Bootstrapped SE & & Bootstrapped SE & \\
\hline $\mathrm{TG}_{91 \_94}=\mathrm{TG}_{95 \_98}$ & 0.935 & $\mathrm{TG}_{91 \_94}=\mathrm{TG}_{95 \_98}$ & 0.904 \\
\hline $\mathrm{TG}_{95 \_98}=\mathrm{TG}_{99 \_02}$ & 0.151 & $\mathrm{TG}_{95 \_98}=\left(\mathrm{TG}_{99 \_02}+\right.$ & 0.141 \\
\hline $\mathrm{TG}_{95 \_98}=\left(\mathrm{TG}_{99 \_02}+\mathrm{TG}_{03 \_07}\right) / 2$ & 0.062 & $\mathrm{TG}_{95 \_98}=\left(\mathrm{TG}_{99 \_02}+\mathrm{TG}_{03 \_07}\right) / 2$ & 0.049 \\
\hline $\begin{array}{l}\left(\mathrm{TG}_{91 \_} 94+\mathrm{TG}_{95} \_98\right) / \\
2=\left(\mathrm{TG}_{99 \_02}+\mathrm{TG}_{03 \_07}\right) / 2\end{array}$ & 0.141 & $\begin{array}{l}\left(\mathrm{TG}_{91}{ }_{94}+\mathrm{TG}_{95} \_98\right) / \\
2=\left(\mathrm{TG}_{99}{ }_{92}+\mathrm{TG}_{03 \_07}\right) / 2\end{array}$ & 0.106 \\
\hline
\end{tabular}


Table 10 Trend in simple and total criminal association in the whole period using the actual value of the Wind Index (1990-2007) (Sample: 19 neighbouring provinces)

\begin{tabular}{|c|c|c|c|c|}
\hline Variables & $\begin{array}{l}\text { (1) } \\
\text { CrimAssoc }\end{array}$ & $\begin{array}{l}(2) \\
\text { CrimAssoc }\end{array}$ & $\begin{array}{l}(3) \\
\text { TCrimAssoc }\end{array}$ & $\begin{array}{l}\text { (4) } \\
\text { TCrimAssoc }\end{array}$ \\
\hline TG_Wind91_94 & $\begin{array}{l}0.154 \\
(0.205) \\
(0.234)\end{array}$ & & $\begin{array}{l}0.297 \\
(0.240) \\
(0.294)\end{array}$ & \\
\hline TG_Wind $95 \_98$ & $\begin{array}{l}0.185 \\
(0.219) \\
(0.325)\end{array}$ & & $\begin{array}{l}0.313 \\
(0.231) \\
(0.366)\end{array}$ & \\
\hline TG_Wind $99 \_02$ & $\begin{array}{l}0.545 \\
(0.314)^{*} \\
(0.452)\end{array}$ & $\begin{array}{l}0.314 \\
(0.152)^{*} \\
(0.169)^{*}\end{array}$ & $\begin{array}{l}0.748 \\
(0.353)^{* *} \\
(0.500)\end{array}$ & $\begin{array}{l}0.362 \\
(0.183)^{*} \\
(0.184)^{*}\end{array}$ \\
\hline TG_Wind $03 \_07$ & $\begin{array}{l}0.950 \\
(0.395)^{* *} \\
(0.616)\end{array}$ & $\begin{array}{l}0.665 \\
(0.186)^{* * *} \\
(0.266)^{* *}\end{array}$ & $\begin{array}{l}1.229 \\
(0.494)^{* *} \\
(0.681)^{*}\end{array}$ & $\begin{array}{l}0.762 \\
(0.237)^{* * *} \\
(0.296)^{* *}\end{array}$ \\
\hline Controls & Yes & Yes & Yes & Yes \\
\hline Province and year FE & Yes & Yes & Yes & Yes \\
\hline Observations & 342 & 342 & 342 & 342 \\
\hline $\mathrm{R}^{2}$ & 0.328 & 0.327 & 0.307 & 0.304 \\
\hline Number of prov_id & 19 & 19 & 19 & 19 \\
\hline
\end{tabular}

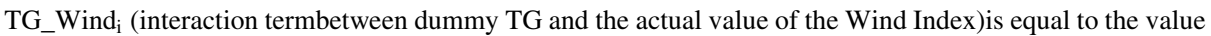
of Wind Index for each province in the treatment group for the period i, and zero otherwise. TG_Wiad is the treatment group fixed effect which varies in the level of the Wind Index. In all columns, OLS regression swim time province fixed effects, province specific time trends and clustered standard errors at the province level (in parenthesis). Control variables included are: School, log of GDP per capita, Population density and Violent crime Index

Significance levels: *** $\mathrm{p}<0.01, * * \mathrm{p}<0.05, * \mathrm{p}<0.1$

Table 11 Test of the coefficients

\begin{tabular}{|c|c|c|c|}
\hline $\begin{array}{l}\mathrm{H}_{0} \\
\text { CrimAssoc }\end{array}$ & $\begin{array}{l}\mathrm{p} \\
\text { value }\end{array}$ & $\begin{array}{l}\mathrm{H}_{0} \\
\text { TCrimAssoc }\end{array}$ & $\begin{array}{l}\mathrm{p} \\
\text { value }\end{array}$ \\
\hline Cluster SE & & Cluster SE & \\
\hline Wind $_{91 \_94}=$ Wind $_{95} \_98$ & 0.842 & Wind $_{91 \_94}=$ Wind $_{95} \_98$ & 0.941 \\
\hline Wind $_{95 \_98}=$ Wind $_{99 \_02}$ & 0.043 & Wind $_{95 \_98}=$ Wind $_{99 \_02}$ & 0.045 \\
\hline Wind $_{95 \_98}=\left(\right.$ Wind $_{99 \_02}+$ Wind $\left._{03 \_07}\right) / 2$ & 0.006 & Wind $_{95 \_98}=\left(\right.$ Wind $_{99 \_02}+$ Wind $\left._{03 \_07}\right) / 2$ & 0.012 \\
\hline $\begin{array}{l}\left(\text { Wind }_{91 \_94}+\text { Wind }_{95 \_98}\right) / \\
\quad 2=\left(\text { Wind }_{99 \_02}+\text { Wind }_{03 \_07}\right) / 2\end{array}$ & 0.019 & $\begin{array}{l}\left(\text { Wind }_{91 \_}{ }_{94}+\text { Wind }_{95 \_98}\right) / \\
2=\left(\text { Wind }_{99 \_02}+\text { Wind }_{03 \_07}\right) / 2\end{array}$ & 0.048 \\
\hline Bootstrapped SE & & Bootstrapped SE & \\
\hline Wind $_{91 \_94}=$ Wind $_{95} \_98$ & 0.873 & Wind $_{91 \_94}=$ Wind $_{95 \_98}$ & 0.941 \\
\hline Wind $_{95 \_98}=$ Wind $_{99} \_02$ & 0.062 & Wind $_{95 \_98}=$ Wind $_{99 \_} \_2$ & 0.037 \\
\hline Wind $_{95 \_98}=\left(\right.$ Wind $_{99 \_02}+$ Wind $\left._{03 \_07}\right) / 2$ & 0.03 & Wind $_{95 \_98}=\left(\right.$ Wind $_{99 \_02}+$ Wind $\left._{03 \_07}\right) / 2$ & 0.017 \\
\hline $\begin{array}{l}\left(\text { Wind }_{91 \_94}=\text { Wind }_{95 \_98}\right) / \\
\quad 2=\left(\text { Wind }_{99} \_02+\text { Wind }_{03 \_07}\right) / 2\end{array}$ & 0.077 & $\begin{array}{l}\left(\text { Wind }_{91 \_94}+\text { Wind }_{95 \_98}\right) / \\
2=\left(\text { Wind }_{99 \_02}+\text { Wind }_{03 \_07}\right) / 2\end{array}$ & 0.057 \\
\hline
\end{tabular}


Table 12 Trend in simple and total criminal association after the introduction of the green certificate system using the actual value of the Wind Index (Sample: 19 neighbouring provinces)

\begin{tabular}{|c|c|c|c|c|}
\hline VARIABLES & $\begin{array}{l}\text { (1) } \\
\text { CrimAssoc }\end{array}$ & $\begin{array}{l}\text { (2) } \\
\text { CrimAssoc }\end{array}$ & $\begin{array}{l}\text { (3) } \\
\text { TCrimAssoc }\end{array}$ & $\begin{array}{l}\text { (4) } \\
\text { TCrimAssoc }\end{array}$ \\
\hline TG_Wind $99 \_00$ & $\begin{array}{l}0.386 \\
(0.217)^{*} \\
(0.205)^{*}\end{array}$ & & $\begin{array}{l}0.370 \\
(0.243) \\
(0.216)^{*}\end{array}$ & \\
\hline TG_Wind $_{01 \_02}$ & $\begin{array}{l}0.323 \\
(0.143)^{* *} \\
(0.222)\end{array}$ & & $\begin{array}{l}0.400 \\
(0.188)^{* *} \\
(0.251)\end{array}$ & \\
\hline TG_Wind $03 \_04$ & $\begin{array}{l}0.611 \\
(0.167)^{* * *} \\
(0.276)^{* *}\end{array}$ & & $\begin{array}{l}0.760 \\
(0.208)^{* * *} \\
(0.309)^{* *}\end{array}$ & \\
\hline TG_Wind $05 \_07$ & $\begin{array}{l}0.813 \\
(0.313)^{* *} \\
(0.413)^{* *}\end{array}$ & & $\begin{array}{l}0.829 \\
(0.372)^{* *} \\
(0.440)^{*}\end{array}$ & \\
\hline POST_Wind $99 \_05$ & & $\begin{array}{l}0.330^{* *} \\
(0.137)\end{array}$ & & $\begin{array}{l}0.386^{* *} \\
(0.146)\end{array}$ \\
\hline Controls & Yes & Yes & Yes & Yes \\
\hline Province and year FE & Yes & Yes & yes & Yes \\
\hline Observations & 342 & 38 & 342 & 38 \\
\hline $\mathrm{R}^{2}$ & 0.330 & 0.550 & 0.304 & 0.490 \\
\hline Number of prov_id & 19 & 19 & 19 & 19 \\
\hline
\end{tabular}

TG_Wind $\mathrm{is}_{\mathrm{i}}$ equal to the value of Wind Index for each province in the treatment group for the period i. and zero otherwise In first and third column, OLS regressions with time province fixed effects, province specific time trends and clustered standard errors at the province levd (in parenthesis), in second and fourth column, paid collapsed in two periods as in Bertrand et al. (2004). POST_Windi $i_{i}$ (interaction term between dummy POST $_{99}$ and the actual value of the Wind Index) is equal to the average value of Wind Index in die treatment group for the post-1999 period and zero otherwise. Control variables included are Sdiool, GDP, Population density and Violent crime fcdex

Significance levels: $* * * \mathrm{p}<0.01, * * \mathrm{p}<0.05 * \mathrm{p}<0.1$

\section{References}

Angrist, J., \& Pische, S. (2009). Mostly harmless econometrics. Princeton: Princeton University Press.

Arezki, R., \& Bruckner, M. (2011). Oil rents, corruption, and state stability: Evidence from panel data regressions. European Economic Review, 55(7), 955-963.

Autor, D. H. (2003). Outsourcing at will: The contribution of unjust dismissal doctrine to the growth of employment outsourcing. Journal of Labor Economics, 21(1), 1-42.

Bertrand, M., Duflo, E., \& Mullainathan, S. (2004). How much should we trust diff-in-diff estimates? Quarterly Journal of Economics, 119(1), 249-275.

Bhattacharyya, S., \& Hodler, R. (2010). Natural resources, democracy and corruption. European Economic Review, 54, 608-621.

Bianchi, M., Buonanno, P., \& Pinotti, P. (2012). Do immigrants cause crime? Journal of the European Economic Association, 10(6), 1318-1347.

Dreher, A., \& Gassebner, M. (2013). Greasing the wheels? The impact of regulations and corruption on firm entry. Public Choice, 155, 413-432.

Ehrlich, I. (1996). Crime, punishment, and the market for offenses. Journal of Economic Perspectives, 10, $43-67$. 
Fisman, R. (2001). Estimating the value of political connections. American Economic Review, 91(4), 1095-1102.

Fisman, R., \& Svensson, J. (2006). Are corruption and taxation really harmful to growth? Firm level evidence. Journal of Development Economics, 83, 63-75.

Fougere, D., Kramarz, F., \& Pouget, J. (2009). Youth unemployment and crime in France. Journal of the European Economic Association, 7, 909-938.

Gennaioli, C., \& Onorato, M., (2010). Public spending and organized crime: The case of the 1997 Umbria and Marche earthquake, Unpublished.

Glaeser, E. L., \& Sacerdote, B. (1999). Why is there more crime in cities? Journal of Political Economy, 107, 225-229.

Gould, D., Weinberg, B., \& Mustard, D. (2002). Crime rates and local labor market opportunities in the United States: 1977-1997. The Review of Economics and Statistics, 84(1), 45-61.

Hessami, Z. (2010). Corruption and the composition of public expenditures: evidence from OECD countries. Munich Personal RePEc Archive.

Kaufmann, D., \& Wei, S. (1998). Does grease money speed up the wheels of commerce?. Mimeo, World Bank.

Levitt, S. D. (1996). The effect of prison population size on crime rates: Evidence from prison overcrowding litigation. Quarterly Journal of Economics, 111, 319-351.

Mauro, P. (1998). Corruption and the composition of government expenditure. Journal of Public Economics, 69, 263-279.

Murphy, K. M., Shleifer, A., \& Vishny, R. (1993). Why is rent seeking so costly to growth? American Economic Review, 83(2), 409-414.

Myrdal, G. (1968). Asian drama: An inquiry into the poverty of nations. New York: Pantheon Books.

Olken, B., \& Pande, R. (2012). Corruption in developing countries. Annual Review of Economics, 4, 479-505.

Sequeira, S. (2012). Advances in measuring corruption in the field. In D. Serra \& L. Watchenkon (Eds.), New advances in experimental research on corruption. Bingley: Emerald Books.

Shleifer, A., \& Vishny, R. (1993). Corruption. Quarterly Journal of Economics, 108(3), 599-617.

Svensson, J. (2005). Eight questions about corruption. Journal of Economic Perspectives, 19(5), 19-42.

Tanzi, V. (1998). Corruption around the world: Causes, consequences, scope, and cures. IMF Working Paper 98/63; Washington: International Monetary Fund.

Tanzi, V., \& Davoodi, H. (1997). Corruption, public investment and growth. IMF working paper 97/139; Washington: International Monetary Fund.

Vincente, P. (2010). oes oil corrupt? Evidence from a natural experiment in West Africa. Journal of Development Economics, 92(1), 28-38. 